\title{
Le français et l'allemand dans l'éducation religieuse en Russie au XVIII ${ }^{\mathrm{e}}$ siècle $^{*}$
}

\author{
Ekaterina Kislova \\ Moscow State University \\ e.kislova@gmail.com
}

\begin{abstract}
«Французский и немецкий языки в духовном образовании 18 века»

Изучение функционирования европейских языков в русском обществе ХVIII в. в настоящее время пользуется вниманием исследователей, однако во всех этих работах внимание сосредоточено на функционировании иностранных языков в светском обществе. Специальных работ, посвященных изучению и употреблению французского и немецкого языков в духовной среде, до настоящего времени не было. Некоторую информацию можно почерпнуть из работ по истории церкви, работ по истории духовного образования и описаний духовных учебных заведений, преимущественно изданных в 19 веке, изучения архивных фондов семинарий, однако отдельным предметом исследования языковая компетенция духовных лиц до нынешнего времени не являлась. В статье рассматривается история преподавания французского и немецкого языков в церковной среде 18 века. На основе опубликованных и архивных источников автор анализирует цели и задачи введения этих языков в духовное образование, историю распространения преподавания европейских языков, описывает сам процесс преподавания языков в семинариях (кто и каким образом обучал и обучался языкам, какие методики были задействованы и какие результаты были достигнуты). Приведенные в статье данные свидетельствуют о том, что некоторая часть священно- и церковнослужителей 18 века получала в семинариях достаточно серьезное образование и приобретала хорошие познания в иностранных языках. Конечно, качественное духовное образование не было массовым, однако реальное состояние духовенства в 18 веке все-таки разительно отличается от того образа необразованных и полуграмотных людей, который складывался на протяжении 18-2о веков.
\end{abstract}

On assiste actuellement à un développement des recherches sur l'utilisation des langues européennes dans la société russe au XVIII ${ }^{\mathrm{e}}$ siècle. Les seuls travaux de E. P. Gretchanaïa, Ju. K. Vorobev et I.V. Sedina, O. Ju. Solodiankina et V. Rjéoutski, ${ }^{1}$ ainsi que le projet de l'université de Bristol, "The History of the French Language in Russia," suffisent à le démontrer. Néanmoins, les chercheurs concentrent leurs études sur l'usage des langues étrangères au sein de la société civile. A ce jour, aucun travail n'a été consacré à l'étude et l'emploi du français et de l'allemand dans la sphère religieuse. On pourra, certes, glaner des informations à partir des recherches réalisées sur l'histoire de l'Eglise, de l'éducation religieuse $^{2}$ et des établissements d'enseignement religieux, essentiellement publiées au XIX ${ }^{\mathrm{e}}$

\footnotetext{
* Ce travail a été réalisé avec le soutien du Conseil des Subventions du Président de la Fédération de Russie pour le soutien aux jeunes chercheurs russes (MK-1573.2013.6). Traduit par Kumar Guha. 1 Е. П. Гречаная, Когда Россия говорила по-французски (Москва: ИМЛИ РАН, 2010); Ю. К. Воробьев, И. В. Седина, Западноевропейские языки в русской культуре (Саранск: Издательство Мордовского университета, 2007); О. Ю. Солодянкина, Иностранные гувернантки в России (вторая половина XVIII первая половина XIX века) (Москва: Academia, 2007); Vladislav Rjéoutski, "La langue française en Russie au siècle des Lumières. Éléments pour une histoire sociale," in Multilinguisme et multiculturalité dans l'Europe des Lumières (Actes du Séminaire international des jeunes dix-huitiémistes 2004), U. Haskins-Gonthier, A. Sandrier (dir.) (Paris: Honoré Champion, 2007), 101-126.

2 Б. В. Титлинов, Правительство Анны Иоанновны в его отношениях к делам православной церкви (Вильна: Типография "Русский почин," 1905); И. К. Смолич, История русской церкви, vol. 8, t. 1 (Москва: Издательство Спасо-Преображенского Валаамского монастыря, 1996); Н. Д. Тальберг, История русской церкви (Москва: Издательство Сретенского монастыря, 1997); Н. М. Никольский, История русской церкви (Москва: Политиздат, 1983).
} 
siècle, ${ }^{3}$ ou à partir de fonds d'archives des séminaires, mais la connaissance des langues au sein de la communauté religieuse n'avait pas encore fait l'objet d'une étude à part entière.

\subsection{L'éducation religieuse en Russie au XVIII' siècle}

Les réformes de Pierre le Grand ont conduit à des changements importants au sein du clergé, en premier lieu du fait des modifications qu'elles ont apportées au modèle d'enseignement russe: l'éducation religieuse cesse d'être dispensée à domicile et revêt un caractère systématique. Elle suit désormais le modèle des établissements ukrainiens, euxmêmes inspirés des collèges jésuites ${ }^{4}$ de l'Ouest de l'Ukraine et de la Pologne. Le "Règlement ecclésiastique" de 1721 fixa le processus de création des écoles, qui relevait jusque-là de l'initiative personnelle des métropolites et des archevêques: dorénavant, chaque diocèse devait ouvrir, dans la maison de l'archevêque, une école destinée aux enfants. Ainsi, en 1764, la Russie comptait 26 séminaires et 20 écoles élémentaires. G.L. Freeze indique les effectifs suivants pour les séminaires: en 1766, 4673; en 1778, 6012; en 1783, 11 329; en 1796, 16 951; en 1799, 20 393; en 1808, 29 000. ${ }^{5}$ Ces chiffres illustrent bien l'augmentation exponentielle de l'enseignement religieux tout au long du siècle. A la fin du XVIII ${ }^{\mathrm{e}}$ siècle, on compte déjà quatre académies (Moscou, Saint-Pétersbourg, Kiev, Kazan), 46 séminaires et tout un réseau d'écoles élémentaires dans les diocèses. ${ }^{6}$

Jusqu'en 1797, la différence entre académie religieuse et séminaire était formelle, en l'absence de programme d'éducation qui les distinguerait. Le cursus présenté dans le "Règlement ecclésiastique" s'envisageait comme un enseignement universel ${ }^{7}$ et organisait les études en quatre étapes:

[...] cours préparatoire, cours élémentaire, cours avancé en latin, cours de philosophie et de théologie. Seul le cours préparatoire prévoit l'enseignement du slavon écrit et parlé. Le cours élémentaire a pour dominante le latin ( 4 ans): latin écrit et parlé, trois années consacrées à la grammaire du latin basée sur celle d'Emmanuel Alvarez en 3 volumes, manuel le plus couramment utilisé à cette époque. ${ }^{8}$

\footnotetext{
3 П. Знаменский, Духовные школы в России до реформы 18о8 года (Казань: Типография Императорского университета, 1881); Д. Вишневский, Киевская академия в первой половине XVIII столетия (Новые данные, относящиеся к истории этой Академии за указанное время) (Киев: Тип. И. И. Горбунова, 19о3); С. Смирнов, История Московской Славяно-греко-латинской академии (Москва: Типография В. Готье, 1855); С. Смирнов, История Троицкой лаврской семинарии (Москва: Типография В.Готье, 1867); Gregory L. Freeze, The Russian Levites. Parish Clergy in the Eighteenth Century (Cambridge, MA/London: Harvard University Press, 1977); А. И. Любжин, Очерки по истории российского образования императорской эпохи. Ученые записки московского культурологического лицея № 1310. Серия: история (Москва: Издательство Московского культурологического лицея, 2000), version électronique (consulté le 25.06.2013).

4 Георгий (Флоровский), Пути русского богословия (Paris: YMCA-Press, 1981), version électronique (consulté le 25.06.2013); К. В. Харлампович, Малороссийское влияние на великорусскую церковную жизнь (Казань: Издание Книжного магазина М. А. Голубева, 1914), vol. 1, 633-740.

5 Freeze, The Russian Levites, 88.

6 Смолич, История, 402, 395, 397.

7 Титлинов, Правительство Анны Иоанновны, 387-388.

8 “[...] preparatory school, elementary school, advanced Latin school, and school of philosophy and theology. Only the preparatory school offered instruction in Slavonic reading and writing. The elementary school devoted almost entirely to Latin (4 years). Reading and writing in Latin; three year program in Latin grammar based on Emmanuel Alvarez's 3 vol. textbook widely used at the time," Freeze, The Russian Levites, 91.
} 
En réalité, l'enseignement était dispensé en fonction des possibilités et des enseignants disponibles localement. ${ }^{9}$ Souvent, il n'y avait pas de cours de niveaux supérieurs:

[...] sur les 26 séminaires ouverts avant 1750, quatre seulement proposaient le cours de théologie (séminaires de Novgorod, Smolensk, la Trinité et le collège de Kharkov), autant, le cours de philosophie (Kazan, Alexandre Nevski, Tver, Pskov). Dans les autres, l'enseignement s'arrêtait au niveau du cours de rhétorique, parfois encore à un niveau inférieur $[\ldots]^{10}$

Jusqu'à la fin du XVIII ${ }^{\mathrm{e}}$ siècle, les établissements religieux étaient ouverts à toutes les couches de la société, ${ }^{11}$ bien qu'en majorité, les élèves fussent issus du clergé. A leur tour, les diplômés issus des séminaires avaient le droit, pratiquement jusqu'à la fin du XIX $\mathrm{X}^{\mathrm{e}}$ siècle, d'entrer dans les académies civiles et les universités. Nombreux étaient ceux qui embrassaient une carrière civile en sortant du séminaire et devenaient, qui traducteur de l'Académie des sciences, qui fonctionnaire du Collège (ministère) des affaires étrangères, ou encore, intégraient le Collège de médecine, par exemple. ${ }^{12}$ L'enseignement religieux en Russie au XVIII était essentiellement basé sur les humanités: on accordait une grande attention au travail sur les textes, pas uniquement théologiques, et, bien entendu, à l'étude des langues étrangères.

\subsection{Langues étudiées dans les séminaires}

On distingue plusieurs groupes de langues enseignées au séminaire:

1) La langue dans laquelle on enseignait, le latin. Les premiers niveaux étaient essentiellement consacrés à son étude (bien plus, d'ailleurs, qu'à celle du russe ou du slavon liturgique). L'enseignement lui-même était dispensé essentiellement en latin (ce n'était qu'après le Règlement de 1840 qu'il devint une matière comme les autres). La versification, la rhétorique, la philosophie et la théologie étaient traditionnellement enseignés en latin. L'expansion du russe comme langue d'enseignement n'intervint que vers la fin du siècle.

2) La "langue naturelle," le russe, qu'on apprenait surtout dans les premiers niveaux comme langue natale, et aussi comme langue officielle de l'Etat. ${ }^{13}$

3) Les "langues théologiques," le grec et l'hébreu, qui étaient les langues nécessaires à la lecture des Ecritures Saintes. Bien que dans la période 1685-1700, l'académie de Moscou des frères Likhoud fonctionnât comme un établissement "helléno-grec," le grec ne l'emportait pas sur le latin et tous les séminaires étaient créés sur le modèle de l'académie de Kiev, donc

\footnotetext{
9 Н. И. Веселовский, Сведения об официальном преподавании восточных языков в России (С.-Петербург: Типография брат. Пантелеевых, 1879), 47.

10 “[...] из 26 семинарий, открытых до 1750 г., богословский курс был только в четырех (Новгородской, Смоленской, Троицкой и в Харьковском коллегиуме), философский в четырех же (Казанской, Александро-Невской, Тверской и Псковской). В прочих преподавание заканчивалось риторикой, даже низшими классами [...],” Харлампович, Малороссийское влияние, 636.

11 Смолич, История, 402; James Cracraft, The Church Reform of Peter the Great (Stanford: Stanford University Press, 1971), 272-275.

12 И. Чистович, История Санкт-Петербургской духовной академии (С.-Петербург: В типографии Якова Трея, 1857), 56-62.

13 Dans les territoires du Sud-Ouest, les langues natales des élèves (l'ukrainien et le biéolorusse) n'étaient pas considérées comme des matières, mais la direction comme les enseignants prenaient soin de différencier le russe des dialectes des élèves en exigeant d'eux une prononciation correcte en russe. Vоir Вишневский, Киевская академия, 123.
} 
avec une dominante latine. ${ }^{14}$ Jusqu'en 1784 , le grec resta une matière optionnelle et ensuite, il devint obligatoire dans tous les séminaires et le niveau de maîtrise de cette langue est mentionné dans les états de service des prêtres et des moines. ${ }^{15}$ Seuls quelques établissements proposaient l'hébreu, mais le Règlement de 1798 le rendit obligatoire dans les académies ecclésiastiques. ${ }^{16}$ Le slavon liturgique faisait également partie des langues théologiques, mais du fait de sa proximité avec le russe, son statut était à part et il s'étudiait plus "par la pratique."

4) Les "langues européennes," dont le polonais, surtout enseigné dans les séminaires du Sud-Ouest et de l'Ouest (académie de Kiev, collège de Kharkov, séminaires de Minsk et Pskov, entre autres); le français et l'allemand, répandus dans la deuxième moitié du XVIII siècle. Certains séminaires incluaient, sur de courtes périodes, l'italien et le néerlandais. ${ }^{17}$

5) Les "langues missionnaires," langue des autres croyants auprès desquels les missionnaires orthodoxes étaient appelés à travailler. A compter de la deuxième moitié du siècle, on enseignait le tatare, le mongol, le tchouvache, etc. Dans les programmes des séminaires, ces langues occupaient la même place que l'hébreu. ${ }^{18}$

Bien entendu, chaque diplômé ne maîtrisait pas toutes ces langues. Il devait au minimum maîtriser le latin. A partir de 1784, une connaissance rudimentaire du grec était souhaitable. Le reste dépendait des capacités et de la volonté de l'étudiant.

\section{Date d'apparition du français et de l'allemand dans les séminaires}

A côté des matières obligatoires, l'enseignement de toute une série de matières (dites "extraordinaires," selon le terme en usage au XVIII ${ }^{\mathrm{e}}$ siècle), pouvait être organisé à n'importe quel moment, à condition qu'il y eût un enseignant, un élève intéressé et que la direction de l'établissement donnât son accord. Ainsi, dès la première moitié du siècle, on voit apparaître des cours particuliers de langues étrangères. Mais, même dans la deuxième moitié, comme ils n'étaient pas obligatoires, leur présence dans un séminaire dépendait surtout du "goût de l'évêque.” En effet, lorsqu'un évêque connaissait le français ou l'allemand, il était fréquent qu'il en introduisît l'enseignement dans son séminaire. Ce fut le cas, par exemple, à Nijni Novgorod, où Théophane (Féodor Tcharnoutski, 1710-1773), ${ }^{19}$ qui parlait le français, ${ }^{20}$ introduisit cette matière dans son séminaire; l'allemand, parlé par Damaskine (Dimitri

14 Смирнов, Московская академия, 17.

15 On distinguait la langue "hellénique," c'est-à-dire la langue classique des écritures saintes et le "romaïque," ou "grec simple," qui est le grec moderne parlé utilisé par l'Eglise grecque. Les étudiants apprennent les deux langues, il est notamment indispensable qu'ils sachent traduire du grec ancien vers le grec moderne et vice versa, en faisant des commentaires grammaticaux (Смирнов, Троицкая семинария, 343).

16 Sur l'enseignement du grec ancien, voir: Е. И. Кислова, “Древнееврейский язык в православных учебных заведениях в России XVIII в. (к истории лингвистической компетенции церковной среды),” Вестник Московского университета. Сер. 9. Филология 1 (2013): 35-50.

17 On enseignait l'italien au collège de Kharkov - voir Любжин, Очерки, 14-15; Antoine Orénove enseigna le néerlandais pendant quelques temps au monastère de la Trinité - voir Смирнов, Троицкая семинария, 352.

18 Веселовский, Сведения, 47.

19 Dans la tradition orthodoxe russe, on change de nom quand on devient moine, nous indiquons donc entre parenthèses le nom civil porté par la personne avant que les voeux fussent prononcés.

20 Макарий (Миролюбов), История Нижегородской иерархии, содержащая в себе сказание о нижегородских иерархах с 1672 до 1850 годах (С.-Петербург: Издание книгопродавца Н. Г. Овсянникова, 1857), 139 . 
Semenov-Roudnev, 1737-1795) qui l'avait appris à Göttingen, fut introduit de la même façon. ${ }^{21}$

Comme le remarquaient déjà les chercheurs au $\mathrm{XIX}^{\mathrm{e}}$ siècle qui tentaient de retracer l'histoire de certains séminaires, le mauvais état de conservation des documents et la difficulté d'accès aux archives des séminaires rendaient difficile la tâche de dresser un tableau exhaustif de l'enseignement religieux au XVIII ${ }^{\mathrm{e}}$ siècle. ${ }^{22}$ Les travaux de You. K. Vorobiev et de I. V. Sedina ${ }^{23}$ présentent brièvement l'enseignement du français et de l'allemand dans les séminaires, mais le tableau qu'ils ont dressé doit être corrigé sur plusieurs points.

L'un des premiers oukases à citer l'enseignement de ces deux langues dans les séminaires est sans doute l'oukase de Pierre II, datant de 1728 , établi en réponse à une demande de Gédéon Vichnevski (1678-1761):

Il convient d'établir des écoles à Smolensk sous l'autorité du monastère de la ville, de recruter des enseignants des monastères de Kiev et des écoles de Moscou, sur instruction du Synode; on y enseignera le latin, le français et l'allemand aux élèves, et pour ceux qui veulent devenir prêtres, le grec également. ${ }^{24}$

Cependant, le document original de cet oukase ne s'est pas conservé et son texte est simplement cité dans un dossier d'archives de 1752. Dans les "Regulae" de Gédéon Vichnevski, ${ }^{25}$ établies à la même époque, on trouve cette obligation d'enseigner le français et l'allemand, mais on ne sait pas si elle a été suivie d'effets. En tout état de cause, on ne trouve aucune trace de tels cours dans les listes d'enseignants de $1745^{-1747}$, et ce n'est qu'après 1761 que l'on voit une classe de français réapparaître. $^{26}$

Les témoignages relatifs au collège de Kharkov sont plus fiables. Lorsque Petr Smelitch (mort en 1744) fut nommé archevêque de Belgorod en 1736, on y ouvrit des cours de français et d'allemand, mais lorsqu'il quitta ses fonctions en 1741, les cours s'arrêtèrent:

Son éminence Petr Smelitch de Belgorod a ouvert dans notre collège des cours de français et d'allemand, de mathématiques, de géométrie, d'architecture, d'histoire et de géographie: à cette fin, il a recruté des enseignants d'établissements à l'étranger et commandé des manuels et des instruments mathématiques. ${ }^{27}$

Ces cours furent rouverts par instruction de Catherine II en 1765: "Aux sciences actuellement enseignées au collège de Kharkov, ajouter des classes de français, d'allemand, de mathématiques, de géométrie, de dessin et particulièrement d'ingénierie, d'artillerie, de géodésie [...].”Néanmoins, ces classes n’ouvrirent qu'en 1768 et furent gérées directement par

21 Я. Горожанский, Дамаскин Семенов-Руднев, епископ Нижегородский (1737-1795); его жизнь и труды (Киев: Типография Г. Т. Корчак-Новицкого, 1894), 233.

22 А. Князев, Очерк истории Псковской семинарии от начала до преобразования ее по проекту устава 1814 года (Москва: Университетская типография, 1866); И. Сперанский, Очерк истории Смоленской духовной семинарии и подведомых ей училищ со времен основания Семинарии до ее преобразования по Уставу 1867 года (1728-1868 г.) (Смоленск: Типография Е. П. Позняковой, 1892), etc.

23 Воробьев и Седина, Западноевропейские языки, 86-91.

24 Сперанский, Очерк истории Смоленской духовной семинарии, 6.

25 Ibid., 20.

26 Ibid., 76.

27 Амвросий (Орнатский), История российской иерархии. Vol. 1 (Москва: Синодальная типография, 1807), $637-638$. 
l'administration du gouvernement. ${ }^{28}$ Le tableau suivant détaille les dates d'apparition des classes de langues étrangères dans les autres établissements:

Tableau 1. Date d'apparition des classes de langues étrangères dans les séminaires ${ }^{29}$

\begin{tabular}{|c|c|c|}
\hline & Classe d'allemand & Classe de français \\
\hline Séminaire Alexandre Nevski & \multicolumn{2}{|c|}{ fin des années 1750, date certaine pour 1772} \\
\hline Séminaire de St Vladimir & présente dans les années 1810 & \\
\hline Séminaire de Voronej & & présente dans les années 1770 \\
\hline Académie de $\mathrm{Kiev}^{30}$ & $\begin{array}{l}\text { 1738-1742 (Simon Todorski), } \\
\text { 1746-1747 (Mikhaïl } \\
\text { Maksimovitch), puis à partir de } \\
1773\end{array}$ & $\begin{array}{l}1753-1758 \text { (Konstantin } \\
\text { Krijanovski) }\end{array}$ \\
\hline Séminaire de Minsk & présente dans les années 1797 & à partir de 1807 \\
\hline Académie de Moscou & présente de 1778 & à partir de 1781 \\
\hline Séminaire de Nijni Novgorod & après 1783 & après 1753 \\
\hline Séminaire de Novgorod & $\begin{array}{l}\text { 1762, Théophile (Raev), ensuite } \\
\text { à partir de } 1800\end{array}$ & \\
\hline Séminaire Pérérvinsk & présente en 1794 & \\
\hline Séminaire de Pskov & de 1774 à 1803 & 1776 uniquement \\
\hline Séminaire de Riazan & après 1778 & à partir de 1765 ou 1766 \\
\hline \multirow[t]{2}{*}{ Séminaire de Smolensk } & & après 1761 \\
\hline & \multicolumn{2}{|c|}{ en 1787 enseignées de façon permanente } \\
\hline Séminaire de Tver & présente en 1802 & présente en 1777 \\
\hline Séminaire de la Trinité & \multicolumn{2}{|l|}{\begin{tabular}{|l} 
à partir de 1763 (Nikolaï Tsvet) \\
\end{tabular}} \\
\hline Collège de Kharkov & \multicolumn{2}{|l|}{$1736-1741$, puis à partir de 1768} \\
\hline
\end{tabular}

E. Chmourlo lie l'apparition, à la fin des années 1760, du français, de l'allemand et d'autres matières non religieuses, aux idées exprimées par Catherine II dans son "Instruction à la commission établie par nous concernant les domaines de l'Eglise" du 29 novembre 1762. ${ }^{31}$ A la suite de considérations sur le faible niveau d'éducation du clergé et sur son incapacité à éduquer le peuple, les points 7 à 10 de l'instruction évoquent l'éducation religieuse et l'organisation des séminaires et "petits gymnases":

28 Амвросий, Российская иерархия, 638-639. Voir aussi: Любжин, Очерки, 14-15.

29 Etabli d'après: Д. Агнцев, История Рязанской духовной семинарии 1724-1840 г. (Рязань: Типография наследников 3. П. Поздняковой, 1889), 113; Амвросий, Российская иерархия, 6о9, 611, 612; М. Вержболович История Минской духовной семинарии. Vol. 1. Дореформенный период (Минск: Типо-литография Б. И. Соломонова, 1893), 62; Горожанский, Дамаскин, 127, 230-233; Знаменский, Духовные школы, 458; Князев, Псковская семинария, 27, 59; В. Колосов, История Тверской духовной семинарии. Ко дню 15о-летнего юбилея семинарии (Тверь: Типография Губернского правления, 1889), 239; Макарий, Нижегородская иерархия, 139, 143; Макарий (Булгаков), История Киевской академии (С.-Петербург: В Типографии Константина Жернакова, 1843), 124, 154-155; К. Надеждин, История Владимирской духовной семинарии (С 1750 года по 1840 год) (Владимир: Печатня А. А. Александровского, 1875), 131-132, 168; Смирнов, Московская академия, 310, 311; Сперанский, Очерк истории Смоленской духовной семинарии, 76; Чистович, Санкт-Петербургская академия, 42; Е. Шмурло, Митрополит Евгений как ученый. Ранние годы жизни. 1767-1804 (С.-Петербург: Типография В. С. Балашева, 1888), 26.

30 N. Grigorovitch indique qu'on continuait d'enseigner le français et l'allemand "entre 1755 et 1765 " (H. Григорович, “Канцлер князь Безбородко (Опыт разработки материалов для его биографии),” Русский архив издаваемый Петром Бартеневым 9 (1874): 585).

31 Шмурло, Митрополит Евгений, 26. 
A ce jour, les séminaires des diocèses ont très peu d'élèves méritants, les séminaristes, dans des établissements faibles en sciences et eux-mêmes entretenus pauvrement, apprennent généralement le grec et le latin auprès d'enseignants inhabiles, ne connaissent aucune autre discipline excepté les bases scolaires du latin et n'apprennent ni les sciences philosophiques et morales, ne connaissent pas l'histoire religieuse ni civile, ni même la situation du globe ou des lieux où vivent les autres peuples. [...] C'est pourquoi nous ordonnons à la Commission, comme œuvre principale de Dieu et comme premier moyen de planter les semences spirituelles, de réfléchir, avec toute l'application qu'il se doit, à la façon de mettre en place, dans tous les diocèses, dans la maison de l'évêché, des établissements conformes au Règlement ecclésiastique, où des élèves sélectionnés apprendront les sciences supérieures, telles que les règles de la rhétorique, la pureté de la langue latine, l'histoire religieuse et civile, la philosophie pratique et la théologie selon les traditions de notre église orthodoxe orientale [...]. ${ }^{32}$

Le texte ne comporte pas d'exigence explicite concernant l'introduction des langues européennes, mais dès les années 1770-1780 elles étaient enseignées dans les séminaires des régions centrales de la Russie. Les évêques y voyaient sans doute un moyen non négligeable et approuvé par le gouvernement de "planter les semences spirituelles."

A. Blagovechtchenski évoque l'importance du "Règlement" dans les établissements d'enseignement publics daté du 3 août 1786 pour le développement de nouvelles langues:

Par un oukase du 27 novembre 1786, le Saint-Synode ordonna de mettre en place dans les écoles religieuses, le système d'enseignement des écoles publiques et d'utiliser leurs manuels les plus courants. Pr. Amvrosi s'empressa d'appliquer cet oukase: il changea la méthode d'enseignement de son séminaire, ajouta de nouvelles matières, comme l'allemand, le français, l'histoire et la géographie, enrichit le cours de mathématiques $[\ldots] .{ }^{33}$

En effet, les paragraphes 11 à 13 donnent des instructions pour l'introduction des langues étrangères:

Dans toutes les Ecoles principales populaires, en dehors des règles de la langue russe comme langue maternelle, on doit enseigner les bases du latin aux élèves qui souhaitent poursuivre un enseignement supérieur dans un gymnase ou une

\footnotetext{
32 “По сие время архиерейские семинарии состоят весьма в малом числе достойных и надежных учеников, в худом учреждении для наук, и в бедном содержании семинаристы нынешние, обыкновенно в некоторых местах обучаются латинскому и греческому языку от неискусных учителей, не знают иных учений, как только самые школьные и первые основания латинского языка, не обучаются ни наук философских и нравоучительных, не знают истории церковной и гражданской, ниже положения круга земного и мест, на которых в рассуждении других народов живут [...]. Чего ради Комиссии повелеваем о сем, яко главном деле Божии, и первом способе к насаждению плодов духовных, всеприлежнейше подумать, каким бы образом во всякой епархии при архиерейском доме завести училищные домы, так, как об них в Регламенте духовном расписано, в которых бы избранные ученики обучалися вышним наукам, яко то правил прямых красноречия, чистоты латинского языка, истории церковной и гражданской, философии практической и богословия по преданиям древнего нашего восточной церкви православия." В. М. Клеандров et al., Законодательство Екатерины II. En 2 vols. Vol. 1 (Mocква: Юридическая литература, 2001), 278-279.

33 А. Благовещенский, История старой Казанской духовной академии. 1797-1818 (Казань: Типография Императорского университета, 1876), 9.
} 
université; de plus, l'apprentissage d'une langue étrangère parlée à côté de chaque gouvernement dans lequel se trouve une Ecole principale, peut être plus utile si cette langue est utilisée dans la vie quotidienne. ${ }^{34}$

On ne cite pas les langues en question et on peut penser qu'il est fait référence aux langues d'autres groupes ethniques vivant en Russie, mais à la fin du Règlement se trouve une annexe, "Instruction aux enseignants de langues étrangères des écoles principales," où, sur l'exemple de l'allemand, on décrit dans le moindre détail les méthodes d'enseignement à toutes les étapes de l'apprentissage de cette langue. ${ }^{35} \mathrm{Il}$ est donc tout à fait évident que pour les contemporains, il s'agissait des langues d'autres pays d'Europe. Vers 1786, le français et l'allemand étaient déjà enseignés dans plusieurs séminaires, mais le Règlement a probablement pu jouer un rôle dans leur introduction dans d'autres établissements.

On peut noter la différence de traitement que le législateur, et à travers lui, l'Etat, accordait aux langues "théologiques" par rapport aux langues “européennes." Le grec et l'hébreu étaient régulièrement cités dans les oukases concernant l'enseignement religieux (en commençant par le "Règlement ecclésiastique" de 1722, puis dans l'oukase d'Anna Ivanovna de $1738^{36}$ sur la création des séminaires, pour ne citer que ceux-là). Cela étant, l'hébreu était rarement enseigné dans les séminaires. ${ }^{37}$ Le français et l'allemand n'apparaissent, quant à elles, que dans diverses dispositions et oukases consacrés à des établissements bien précis (cf. l'oukase de Pierre II de 1728, le rescrit de Catherine II sur le séminaire Alexandre Nevski du 10 mai 1788, etc.). Ces langues étaient pourtant déjà enseignées dans certains séminaires. Les langues modernes étaient vraisemblablement considérées comme relevant de l'éducation laïque, tandis que les langues telles que le latin, le grec ou l'hébreu, plus importantes pour le clergé, étaient toujours considérées comme des langues religieuses.

Néanmoins, au sein du clergé, dès les années 1770, on considérait le français et l'allemand comme un élément important de l'enseignement religieux. Ainsi, la commission ecclésiastique, à l'occasion d'un avis qu'elle émit sur la faculté de théologie de l'université de Moscou, releva la nécessité d'avoir "un gymnase dépendant de la faculté," où les élèves venant du séminaire "pourraient assister aux cours de physique, mathématiques, philosophie morale, antiquité et histoire naturelle, et de langues: hébreu, grec, français, allemand [mes italiques-E.K.]." ${ }^{38}$ Ici, la commission met les langues européennes sur un pied d'égalité avec les langues théologiques.

Cependant, ce ne fut qu'après le Règlement de 1798 que le français et l'allemand furent officiellement introduits dans les programmes des séminaires et des académies religieuses, et encore, seulement comme langues facultatives, au contraire du grec et de l'hébreu, obligatoires, et leur enseignement fut sujet aux "nécessités du diocèse." Le séminariste devait néanmoins connaître désormais au minimum l'une de ces langues: "[enseigner] les langues allemande et française, selon le souhait de l'élève et les nécessités du diocèse, de façon à ce que chaque étudiant apprenne au moins l'une d'elles." ${ }^{39}$ En conséquence, au

34 Полное собрание законов Российской империи. Т. XXII. C 1784 по 1788 (С.-Петербург: Типография II Отделения Собственной Его Императорского Величества Канцелярии, 1830), 647-648.

35 Ibid., 659-662.

36 Амвросий, Российская иерархия, 564-565.

37 Кислова, “Древнееврейский язык,” 40-42.

38 X., “Проект богословского факультета при Екатерине II,” Вестник Eвponы IV (1873): 313-314. Article publié sous l'initiale X., auteur inconnu.

39 Полное собрание законов, vol. XXV, 428. 
début du XIX ${ }^{\mathrm{e}}$ siècle, on voit apparaître des classes de l'une ou l'autre langue, même dans les établissements les plus pauvres ou les plus éloignés.

En 1794, suite aux événements révolutionnaires en France, l'enseignement du français dans les séminaires fut interdit. A l'été 1794, le métropolite de Novgorod, Gavriil (Piotr Petrov-Chapochnikov, 1730-1801), adressa une lettre aux diocèses dont le message principal était: "Vos séminaristes apprennent le français, comme l'expérience montre que, les mal intentionnés parmi eux utilisent la connaissance de cette langue à mauvais escient, il m'a été demandé d'écrire à votre Eminence pour lui demander de bien vouloir arrêter ces cours." ${ }^{\circ}$ Les cours furent alors suspendus et, dans certains séminaires, on confisqua les manuels aux élèves et aux enseignants pour les consigner à la bibliothèque. ${ }^{41}$ Au séminaire de la Trinité, cependant, l'interdiction ne fut pas complète: dans le recueil manuscrit des louanges adressées au métropolite Platon (Piotr Levchine, 1737-1812) en 1795 et 1796, certains élèves de la classe de théologie, de philosophie et de rhétorique ${ }^{42}$ écrivirent des stances et des épigrammes en français, quant aux élèves de théologie et de philosophie, ils composèrent en français une petite pièce en vers, ainsi que quelques stances. ${ }^{43}$

Au séminaire de la Trinité Saint-Serge, le français fut rétabli dès $1797 .{ }^{44}$ Cette réhabilitation rapide s'explique par son statut dont il jouit de fait de séminaire de la cour: en réponse, semble-t-il, à une demande du métropolite Platon (Levchine), l'empereur Paul, visitant le monastère, autorise verbalement la réouverture de la classe de français, comme en témoigne un oukase spécial: "Sa Majesté impériale, Seigneur illustrissime autocrate de toute la Russie, Paul Pétrovitch, se trouvant, le 24 avril 1797 en sa très haute personne au monastère de la Trinité et faisant grâce de sa visite au monastère de Béthanie, y donna par oral la très gracieuse autorisation de continuer l'enseignement du français au séminaire de la Trinité et à cette fin d'y ouvrir une classe: et pour cela, informer l'administration du séminaire de l'autorisation de sa très haute Majesté impériale, afin qu'elle nous présente le projet d'ouverture de cette classe. Signé: Platon M. et A., le 26 avril 1797." 45 Les cours de français reprirent au séminaire de Voronej et à l'académie de Kiev en 1798, à l'académie de Moscou en 1800, à Riazan vers 1800 et à Tver en $1802 .{ }^{46}$ Le français fut à nouveau autorisé dans les autres séminaires vraisemblablement à la même époque.

\section{Les enseignants de français et d'allemand.}

Les enseignants d'allemand et de français dans les séminaires, comme dans les autres établissements d'enseignement en Russie, pouvaient être des étrangers ou bien des Russes ayant étudié à l'étranger ou ayant étudié une langue étrangère en Russie (dans des écoles laïques ou religieuses). Cependant, les particularités des établissements religieux imprimaient leur marque sur le choix de l'enseignant et le travail qui leur était confié.

\subsection{Les enseignants étrangers}

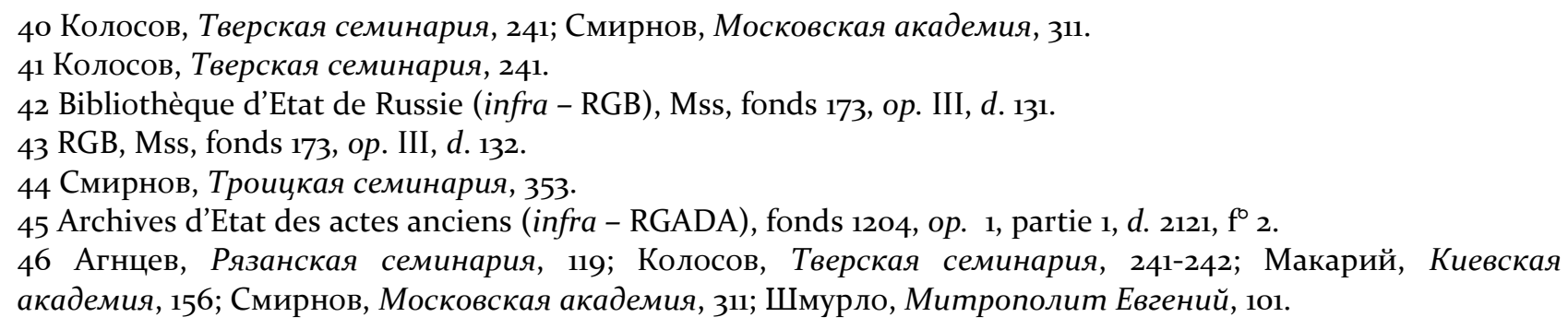


Durant tout le XVIII ${ }^{\mathrm{e}}$ siècle, les enseignants de langues étrangères furent principalement des étrangers (catholiques ou protestants). ${ }^{47}$ Les responsables des séminaires craignaient que le contact avec des représentants d'autres confessions "ne port[ât] atteinte à la foi orthodoxe," crainte partagée d'ailleurs par les établissements laïques également. Ainsi, le "comte Egor Alexandrov Von Ranz" [Ranzau], un catholique, donnait des cours particuliers "de français et d'allemand (et peut-être aussi d'autres dialectes) à douze enfants de divers rangs." ${ }^{8}$ Ce qui ne manqua pas de provoquer la réaction de Gédéon Vichnevski: "[...] interdire au dit comte Egor Von Ranz de tenir une école publique et d'enseigner à des enfants de différentes personnes; car il est dangereux et suspect que de jeunes enfants se trouvent sous la surveillance et ne reçoivent d'enseignement que d'une personne d'une autre croyance, car ils pourraient recevoir une instruction qui serait contraire à la croyance gréco-russe orientale orthodoxe." ${ }^{49}$ Néanmoins, si le comte lui-même souhaitait "dans les écoles de Smolensk citées ci-dessus, dispenser un enseignement sous le contrôle $d u$ recteur [mes italiques - E.K.], alors le consistoire pourrait examiner sa demande." ${ }^{\circ}$

L'obligation d'introduire les langues étrangères conduisit néanmoins à quelques compromis et on fit appel éventuellement aux services des chrétiens d'autres confessions: les premiers enseignants de langues étrangères dans les séminaires, dans les années 1750-1760, étaient des étrangers. En 1781, ce fut un Allemand, Johan Schmidt, qui enseignait le français et l'allemand à l'Académie de Moscou. Mais lorsque le lecteur de l'université de Moscou, Heim, voulut candidater à sa suite, le métropolite Platon (Levchine) lui opposa un refus: on eut déjà le temps de préparer la relève au sein de l'Académie et l'enseignement fut confié à un ancien élève, Nikolaï Sokolov. ${ }^{51}$ Au monastère Alexandre Nevski, on recrutait aussi des étrangers: "Les cours de français et d'allemand furent assurés quelques temps par le professeur Gutzman [?]. Pour le remplacer, on fit ensuite appel à Karl Volmer [?], venu de l'Institut impérial pour jeunes filles nobles [...] mais ce dernier quitta ses fonctions au bout d'un an. Les lecteurs qui travaillèrent avec eux étaient des étudiants: Nikolaï Znamenski (qui devint par la suite recteur de l'Académie), Nikolaï Annenski et Ivan Dankov." ${ }^{2}$ Dans les années 1770, au séminaire de Voronej, le français fut enseigné par Stelter; à partir de 1788, au séminaire de Kiev, c'est "l'étranger Remer [?]" qui enseignait l'allemand, puis, à partir de 1801, ce poste revint à "Samoïlo Khrapopov, originaire des régions de César" (le Saint Empire Romain Germanique). ${ }^{53}$ Suite à la disposition de Gédéon (Grigori Krinovski, 1726-1763) en 1758, le séminaire de la Trinité invita le Français Jean (Iogann/Jagan) Debelier [?], qui habitait Moscou et donnait des cours particuliers de français et d'allemand dans le Faubourg des étrangers (Nemetskaïa Sloboda) aux enfants de notables. ${ }^{54}$ Cependant, le contrat ne fut pas signé et le séminaire envoya deux étudiants à l'université de Moscou spécialement pour y apprendre les langues afin de revenir les enseigner.

\footnotetext{
47 Voir pour plus de détails : Солодянкина, Гувернантки; Anne Mézin et Vladislav Rjéoutski (dir.), Les Français en Russie au siècle des Lumières. Dictionnaire des Français, Suisses, Wallons et autres francophones européens en Russie de Pierre le Grand à Paul I ${ }^{e r}$ (Ferney-Voltaire: Centre international d'étude du XVIII ${ }^{\mathrm{e}}$ siècle, 2011), 2 vol.

48 Сперанский, Очерк истории Смоленской духовной семинарии, 45.

49 Ibid., 46.

50 Ibid.

51 Смирнов, Московская академия, 310.

52 Чистович, Санкт-Петербургская академия, 87.

53 Шмурло, Митрополит Евгений, 27; Макарий, Киевская академия, 154.

54 Смирнов, Троицкая семинария, 53.
} 
Dès qu'elles le pouvaient, les directions des séminaires remplaçaient les étrangers par leurs propres diplômés. L'Académie de Kiev fit figure d'exception: après Konstantin Krijanovski, le français était dispensé "en majeure partie par des Français de souche": Margast de Zeemilière (1770-1776), ${ }^{55}$ Vassili Liuppa [?] (à partir de 1778), Forenelle (à partir de 1789), "Carl Compagnon, capitaine de réserve" (à partir de 1802), Petr Greco [?] (à partir de 1811). ${ }^{56}$ Cette particularité s'explique par les contacts intensifs avec les étrangers qui avaient lieu au sein de cette Académie où la crainte "d'atteinte à la foi" était moins grande: tout au long des $\mathrm{XVIII}^{\mathrm{e}}$-XIX ${ }^{\mathrm{e}}$ siècles, on envoya les élèves poursuivre leurs études dans différents pays d'Europe ce qui ne les empêchait pas, à leur retour, d'entrer dans les ordres.

Le cas d'Antoine Orénove [?] est un exemple assez rare de relation avec un étranger dans un séminaire, après l'introduction des langues étrangères. ${ }^{57}$ En 1785 , le métropolite Platon (Levchine) lui offrit de venir enseigner au séminaire de la Trinité; Orénove y enseigna le français, l'allemand, le néerlandais et aussi "le globe et la géographie." ${ }^{8}$ En février et en août 1785, Orénove enseigna les langues en qualité d'assistant d'Ivan Sokolski, et lorsque ce dernier fut transféré à l'Académie de Moscou, il devint enseignant à part entière. Le 16 décembre 1786, Orénove et son épouse furent battus et volés, et, en février 1787 , Orénove reçut une attestation et quitta la Laure peu après. ${ }^{59}$ Il n'y a plus d'information les concernant après cette date. Dans l'ensemble, les responsables de séminaires tentaient d'éviter d'accueillir des étrangers dans leurs murs et n'examinaient leur candidature à un poste qu'en cas d'absolue nécessité.

\subsection{Les enseignants civils}

Les premiers temps, une forme de compromis pouvait être trouvée: les langues pouvaient être enseignées par un individu qui se trouvait dans un établissement religieux pour une raison ou une autre, et qui connaissait les langues étrangères grâce à des fonctions occupées dans la vie civile. Il pouvait s'agir, par exemple, d'un fonctionnaire logeant au monastère ou d'un militaire désireux d'entrer en religion. Ces enseignants étaient également peu nombreux.

Ainsi, on commença à apprendre le français et l'allemand au monastère de la Trinité lorsqu'en 1763 apparut Nikolaï Tsvet, fonctionnaire hébergé chez Dimitri (Daniil Setchenov, 1709-1767), qui entra plus tard dans les ordres. S'ajoutèrent ensuite aux effectifs d'enseignants, en 1767-1768, Fédor Karjavine (1745-1812), qui avait étudié à Paris, ${ }^{60}$ et même

55 Voir sa notice biographique: “Zeemilière, Nicolas de. Maître d’une pension éducative à Moscou en 1766. Il y acceptait des élèves de tout état, mais surtout des enfants de marchands car "ils ont moins d'occasion d'apprendre la Loi Divine et encore moins les langues étrangères et les sciences libres.” Il entendait leur enseigner le français, l'allemand, l'histoire, la géographie. Cette pension était située chez le sacristain de la cathédrale de l'Assomption et le catéchiste de l'Université de Moscou Piotr Alekseev, dans sa maison à Bersenevka, derrière la rivière Moskova," Les Français en Russie, vol. 2, 837.

56 Макарий, Киевская академия, 154.

57 Antoine Orénove était un Français du Languedoc, il étudia à Montpellier puis à Paris, ensuite, il partit étudier dans les universités allemandes, dont celle de Heidelberg, et fut pasteur à Halle. A un moment donné, il s'installa à Saint-Pétersbourg où il enseigna les "nouvelles langues," ouvrit un pensionnat à Volotchok et, en 1784, il proposa ses services au métropolite Platon, en qualité d'enseignant des langues et traducteur de ses sermons en français et en allemand (Смирнов, Троицкая семинария, 510).

58 Смирнов, Троицкая семинария, 352.

59 RGADA, fonds 1204, op. 1, d. 1389.

6o Fedor Karjavine était le fils d'un vieux marchand vieux-croyant. Il étudia en France entre 1753 et 1765, suivit des cours à la Sorbonne où il apprit le français, l'italien, le grec et le latin. A son retour en Russie, il travailla à la 
Ilia Tchistiakov, un aveugle protocoliste de collège, ${ }^{61}$ qui logeait au monastère. On lui ordonna de parler aux élèves en français ou en allemand. ${ }^{62}$ Plus tard, on fit aussi appel à d'autres personnages civils connaisseurs de ces langues: on leur assigna la fonction d'assistant des enseignants (par exemple, Mikhail Mikhaïlovitch Vycheslavtsev, 1757/58années 1830, du régiment de la garde à cheval, issu de la noblesse, qui, à 29 ans, exprima le souhait d'apprendre la théologie). ${ }^{63}$ Néanmoins, les responsables de séminaires se fixaient comme objectif de former leurs propres éducateurs pour disposer de diplômés orthodoxes maîtrisant l'allemand et le français.

\subsection{Les séminaristes diplômés}

L'étudiant du séminaire pouvait étudier les langues étrangères soit à l'étranger, soit dans les écoles laïques en Russie (le plus souvent à l'université de Moscou), soit dans un établissement d'enseignement religieux proposant déjà ces matières.

\subsubsection{Séminaristes ayant étudié à l'étranger}

Les établissements éducatifs religieux emboîtaient le pas aux établissements civils en envoyant leurs meilleurs élèves à l'étranger pour leur faire apprendre les langues et les sciences. ${ }^{64}$ A la fin du XVII ${ }^{\mathrm{e}}$ siècle, les étudiants de l'Académie de Kiev partaient le plus souvent dans des pays catholiques: Théophane (Eléazar Prokopovitch, 1681-1736), futur archevêque et de fait dirigeant de l'Eglise orthodoxe, proche de Pierre $\mathrm{I}^{\mathrm{er}}$, à sa sortie de l'Académie de Kiev, poursuivit ses études dans le collège Saint-Athanase à Rome; Stéphane (Siméon Iavorski, 1658-1722), futur métropolite de Riazan et de Mourom, et futur président du Synode, suivit les enseignements des écoles catholiques de Lvov, Lublin, Poznań et Vilno. Jusqu'à la fin du XVIII ${ }^{\mathrm{e}}$, il était de tradition d'envoyer des élèves de Kiev à Presbourg (aujourd'hui Bratislava, Slovaquie): ce fut le cas d'Anatoli Statski, enseignant d'allemand à partir de 1788, qui avait aussi étudié en Pologne et en Hongrie, d'Irineï (Ivan Falkovski, 17621823), de Samuel Khrappanov, qui enseignait l'allemand en $1797 .{ }^{65}$

Les universités protestantes allemandes et hollandaises étaient aussi prisées: Halle, Göttingen, Leyde, etc. Les élèves en partance n'étaient pas obligés de connaître la langue du pays de destination puisqu'à l'époque, la langue universelle pour la science et les études était le latin. Néanmoins, certains étudiants tentaient d'apprendre l'allemand avant leur départ “à partir des conversations et de la lecture des livres”66 ou dans des établissements éducatifs, comme dans le cas de Simon (Siméon Todorski, 1701-1754) qui, avant son départ pour Halle,

\footnotetext{
Chancellerie pour les étrangers et enseigna ensuite le français pendant deux ans au séminaire de la Trinité. A partir de 1769, à la demande de V.I. Bajenov, il fut affecté au Bureau des constructions du Kremlin. En 1771, il passa l'examen d'enseignant de français à l'université de Moscou. Ecrivain, traducteur, éditeur, voyageur. Voir: С. Р. Долгова, “Каржавин Федор Васильевич,” Словарь русских писателей XVIII века, vol. 2 (К-П) (С.Петербург: Наука, 1999).

61 Kollejski protokolist, l'un des rangs les plus bas selon la table des rangs.

62 Смирнов, Троицкая семинария, 348-349.

63 Ibid., 352.

64 Voir П. Пекарский, Наука и литература в России при Петре Великом. En 2 vol. Vol. 1 (С.-Петербург: Издание товарищества “Общественная польза,” 1862), 220-228; С. Трегубов, Религиозный быт русских и состояние духовенства в XVIII в. по мемуарам иностранцев (Киев: Типография Г. Т. Корчак-Новицкого, 1884), 191-192.

65 А. Белгородский, Киевский митрополит Иерофей Малицкий (1796-1799 г2.) (Киев: Тип. И. И. Горбунова, 1901), 176-177; Макарий, Киевская академия, 154-155.

66 X, Богословский факультет, 311.
} 
apprit l'allemand à l'école de l'Académie des sciences de Saint-Pétersbourg et passa encore un an à Revel. ${ }^{67}$

Les documents témoignent des objectifs assignés aux séminaristes à l'étranger: “[...] par décision du métropolite de Kiev, envoyer à l'étranger des étudiants pour acquérir les meilleures connaissances en sciences afin de pourvoir l'académie en enseignants de qualité" [mes italiques - E.K.]. ${ }^{68}$ C'est sur la base de cet oukase que deux étudiants furent envoyés au couvent réformé de Sloutsk pour apprendre l'allemand, le français et le polonais. Avant leur départ, les étudiants s'engagèrent par écrit à revenir à l'issue de leur formation pour enseigner à l'Académie de Kiev. ${ }^{69}$

Le projet de création d'une faculté de théologie à l'université de Moscou était, lui, d'une plus grande envergure. ${ }^{70}$ Afin de le mettre en place, on envoya seize personnes dans les universités allemandes et anglaises, des séminaristes accompagnés d'inspecteurs. Les informations contenues dans les comptes rendus et les résultats d'examen des séminaristes revenus de ce voyage permettent de savoir en quoi leur formation consista. Ainsi, Dmitri Semenov-Roudnev (Damaskine), qui, avant son départ pour l'université de Göttingen, n'étudia que le latin, le grec et l'hébreu, écrivit dans son rapport qu'il apprit l'allemand "à partir des leçons et des échanges avec le professeur," le français "chez le professeur de français Colon du Clos et auprès des professeurs de rhétorique." ${ }^{71}$ Rozanov et Andreevski, en plus de l'allemand et du français, étudièrent l'anglais; Novikov, lui, se concentra particulièrement sur le français. ${ }^{72}$ L'examen de langue du groupe de Göttingen, mené par les académiciens Krafft et Lexman, et par les inspecteurs du gymnase de l'académie Bacmeister et Stritter le 8 octobre 1773, confirma leur parfaite connaissance des langues, sauf peut-être pour Semenov dont la "diction n'[était] pas du tout bonne."73

Cependant, peu d'entre eux enseignèrent effectivement par la suite les langues ainsi apprises. Petr Rozanov, qui étudia à Göttingen entre 1772 et 1780 , enseigna le français, l'allemand et les mathématiques au séminaire Alexandre Nevski, ${ }^{74}$ Vassili Antonski enseigna l'hébreu, le grec et le français à l'Académie de Moscou. ${ }^{75}$ Mais certains enseignèrent d'autres matières. Martyn Klevetski, qui étudia à Leyde, enseigna à son retour l'histoire, la géographie et le grec; Bykov devint enseignant des "matières théologiques" au séminaire de la Trinité, ${ }^{76}$ Egor Andreevski dispensa des cours de philosophie au séminaire de Novgorod. ${ }^{77}$

Envoyer des étudiants à l'étranger était une entreprise complexe et onéreuse, c'est pourquoi les heureux élus étaient, soit des étudiants recommandés (Simon Todorski fut envoyé grâce à son protecteur Théophane Prokopovitch), soit des étudiants faisant partie du projet pédagogique spécifique d'un établissement (comme dans le cas de l'Académie de Kiev) ou de l'Etat (création de la faculté de théologie à l'université de Moscou).

\footnotetext{
67 Voir Владимирский-Буданов, “Из истории русского просвещения. Первая гимназия в России,” Педагогический музей (1876): 1-3.

68 L'oukase de Catherine II à l'Académie de Kiev du 15 mars 1787, cité d'après: Амвросий, Российская иерархия, 496.

69 Знаменский, Духовные школы, 682.

70 См.: Х, Богословский факультет, 300-317.

71 Горожанский, Дамаскин, 68.

72 X, Богословский факультет, 311.

73 Ibid., 312.

74 Чистович, Санкт-Петербургская академия, 42.

75 X, Богословский факультет, 317.

76 Чистович, Санкт-Петербургская академия, 42; Х, Богословский факультет, 309.

77 И. Л. Григорьева, Н. В. Салоников, “Новгородская духовная семинария: 1740-1918 гг. (К 27о-летию со дня основания),” Вестник Новгородского государственного университета 63 (2011): 36.
} 
3.3.2. Séminaristes ayant étudié en Russie

Il n'était pas rare que les très bons élèves des derniers niveaux d'un séminaire fussent envoyés dans un autre établissement pour y suivre un enseignement spécifique ou approfondir leurs connaissances. Au sein d'un diocèse, jusqu'à la fin du XVIII ${ }^{\mathrm{e}}$ siècle, c'étaient les évêques et les archevêques qui organisaient et finançaient ce type de "formation continue"; à partir du 11 janvier 1798, un oukase définit les conditions d'envoi des meilleurs élèves de quatre académies religieuses; ce même oukase interdit l'envoi des élèves dans des établissements civils. ${ }^{78}$

Les établissements d'enseignement religieux faisant autorité étaient le séminaire de la Trinité, l'Académie de Moscou et le séminaire Alexandre Nevski. Entre 1799 et 1804, deux étudiants du séminaire de Smolensk allèrent étudier à l'Académie de Moscou et, à leur retour, commencèrent à enseigner l'hébreu et l'allemand. ${ }^{79}$ Pendant trente ans, les meilleurs élèves du séminaire de Pskov, destinés à l'enseignement, furent envoyés au séminaire de la Trinité, “réputé à l'époque pour l'excellence de son enseignement des sciences et des langues." ${ }^{80}$ A partir de 1792, on envoya ces élèves au séminaire Alexandre Nevski. De nombreux enseignants des séminaires de Tver, Kazan et d'ailleurs finirent leurs études au séminaire de la Trinité. ${ }^{81}$ Le niveau moyen des cours du séminaire de la Trinité était si élevé que, d'après Smirnov, jusqu'à l'oukase de 1798, il "pourvo[yait] [en enseignants, les séminaires de] Tver, Novgorod, Pskov, Kostroma, Iaroslavl, Kazan, Vladimir, Kalouga, Toula, etc." 82 Certains enseignants de ce séminaire passaient même parfois à l'Académie de Moscou. $^{83}$

Le fait qu'un évêque ou un archevêque avait lui-même étudié au séminaire de la Trinité ou à l'université de Moscou jouait un rôle important lorsqu'ils avaient à leur tour la charge d'organiser le programme de leur séminaire de province: Amvrossi (Andreï Podobedov, 17421818), Iossaf (Ivan Zabolotski, 1744-1788), Damaskine (Semenov-Roudnev) pour ne citer qu'eux. Ces responsables, qui avaient reçu une éducation de grande qualité et qui maîtrisaient non seulement le latin, mais aussi le grec, le français ou l'allemand, tentaient à leur tour de mener leur établissement vers l'idéal établi par le métropolite Platon (Levchine) pour le séminaire de la Trinité.

Les académies religieuses et les meilleurs séminaires étaient toutefois spécialisés dans les matières "théologiques." Il se peut que le français ou l'allemand y fussent bien enseignés, mais on estime que dans certains établissements civils, le niveau était meilleur. C'est pourquoi les séminaristes de province qui en avaient la possibilité allaient à l'université de Moscou pour étudier les langues étrangères, ${ }^{84}$ mais allaient à l'académie de Moscou pour suivre les cours de théologie. Ainsi, Evgeni (Evfimi Bolkhovitinov, 1767-1837) fut envoyé du séminaire de Voronej à l'Académie de Moscou pour

y suivre le programme complet de philosophie puis de théologie et, en plus de cela, le grec et le français; dans le même temps, il s'inscrit à l'université de Moscou où il suit les

78 Амвросий, Российская иерархия, 453-454; Князев, Псковская семинария, 46.

79 Сперанский, Очерк истории Смоленской духовной семинарии, 117.

8 Кн Княев, Псковская семинария, 45.

81 Колосов, Тверская семинария, 178; Знаменский, Духовные школы, 683; А. Благовещенский, История старой Казанской духовной академии. 1797-1818 (Казань: Типография Императорского университета, 1876), 9 .

82 Смирнов, Троицкая семинария, 547.

83 Ibid., 352.

84 Знаменский, Духовные школы, 682-683. 
cours de philosophie morale et de politique auprès de Johannes Matthias Schaden, de physique expérimentale chez Joannes Joachimus Julius Rost, de français et de rhétorique française avec Baudouin, et d'allemand avec Heim. ${ }^{85}$

Bien que le séminaire de Voronej proposât des cours de français et d'allemand, Bolkhovitinov, pour une raison inconnue, ne les suivit pas avant son arrivée à Moscou. ${ }^{86} \mathrm{~A}$ son retour à Voronej en 1789 , il fut immédiatement affecté comme enseignant de rhétorique et de français. ${ }^{87}$

Des étudiants du séminaire de Smolensk étudiaient également le français à l'université de Moscou: “[...] afin d'introduire les belles sciences, [Parfeni] a envoyé des étudiants à l'université de Moscou afin qu'ils puissent ensuite enseigner le français, le grec simple, l'histoire, la géographie et les mathématiques [...]." ${ }^{88}$ Il n'était pas rare non plus que même les étudiants de l'Académie de Moscou et du séminaire Alexandre Nevski vinssent suivre des cours à l'université de Moscou. ${ }^{89}$

Les responsables des séminaires percevaient souvent comme un danger le fait d'envoyer leurs étudiants à l'université, car cela pouvait les détourner de la vocation religieuse. On leur demandait alors de s'engager par écrit à rester fidèles à leur vocation religieuse; ils continuaient, pendant ce temps, d'être comptés dans les effectifs de leur séminaire ou de leur académie d'origine. ${ }^{90}$ Malgré tout, nombre d'entre eux ne revinrent pas. ${ }^{91}$ Les étudiants trouvaient, dans les études à l'université, un moyen d'entrer dans le monde civil; ainsi, Damaskine (Semenov-Roudnev) écrivit:

Les séminaristes d'ici [...] qui ont fait leurs études à l'académie de Moscou sont venus me voir ces jours-ci pour me demander l'autorisation d'étudier à l'Académie et ensuite à l'université de Moscou: mais comme j'ai compris d'après leur discours, qu'ils ont l'intention, grâce à l'université [mes italiques - E.K.], de recevoir une autre carrière, j'ai décidé de les garder ici. ${ }^{92}$

Les diplômés de théologie connaissant le français et l'allemand étaient très demandés. Il n'était pas rare qu'on les retirât d'un séminaire pour les envoyer en mission à l'étranger. Ainsi, Gavriil Dankov (mort en 1805), qui avait enseigné l'allemand au séminaire Alexandre Nevski, fut envoyé comme prêtre à l'ambassade russe à Berlin en $1782 ;{ }^{93}$ Nikolaï Tsvet, qui venait de commencer à dispenser des cours de français et d'allemand au séminaire de la Trinité en 1763, fut intégré à une mission à Pékin en $1767 .{ }^{94}$

85 Шмурло, Митрополит Евгений, 57.

86 Ibid., 58; А. Николаев, “Списки воспитанников, окончивших полный курс семинарских наук в Воронежской духовной семинарии за истекшее столетие,” Приложение к Воронежским епархиальным ведомостям (1882), 46-47.

87 Шмурло, Митрополит Евгений, 100.

88 Д.Н. Мурзакевич, История губернского города Смоленска от древнейших времен до 1804 года. Собранная из разных летописей и российских дееписателей (Смоленск: При Губернском правлении, 1804), 211; voir aussi Знаменский, Духовные школы, 684.

89 Знаменский, Духовные школы, 683.

90 Ibid., 683.

91 Ainsi, ni Bachilov, ni Anitchkov, envoyés du séminaire de la Trinité à l'université en 1763, n'enseignèrent les langues de retour au séminaire. Bachilov enseigna les mathématiques puis, en 1765, devint traducteur à l'Académie des sciences; Ivan Anitchkov enseigna plus tard la jurisprudence à l'université.

92 Горожанский, Дамаскин, 235.

93 Чистович, Санкт-Петербургская академия, 55, 87.

94 Смирнов, Троицкая семинария, 348. 
Souvent, contre le souhait des responsables du séminaire, les enseignants choisissaient le monde laïc. Alexandre Nikolski (1754/55-1834), par exemple, demanda, en 1780, à prendre ses fonctions dans le civil:

Admis dans ce séminaire en 1765, le 12 octobre, ayant commencé dès la première année et continué jusqu'à la Théologie et engagé le 29 septembre de l'année dernière, 1776, comme enseignant de première année, et, depuis juillet 1778, comme enseignant de français et d'allemand jusqu'à ce jour. Mais étant donné que mon âge (car j'ai déjà 27 ans révolus) ainsi que d'autres circonstances m'obligent à choisir un autre état; et que ma préférence va uniquement à une carrière civile: je souhaite entrer dans cette carrière, d'autant plus que j'ai l'espoir d'y occuper un poste décent et profitable: à cette fin [...] je demande très humblement d'être démis de ce séminaire [...]."95

Cependant, après que ses élèves aient été interrogés par le recteur, il apparut que "bien qu'il y ait de bons élèves parmi eux, ils ne peuvent encore enseigner les langues." ${ }^{6}$ C'est pourquoi on demanda à Nikolski de préparer deux élèves pour le remplacer avant de quitter le monastère.

Le faible salaire des enseignants et l'importante demande en personnes maîtrisant les langues étrangères conduisirent à des remplacements fréquents de professeurs, et expliquent aussi que les assistants et les enseignants étaient souvent de jeunes élèves, parfois suivant le cours de théologie. Ceux-ci considéraient cette activité comme transitoire, en attendant d'accéder à un poste dans le civil ou d'entrer dans les ordres pour débuter une carrière religieuse. Seuls Nikolski et Vycheslavtsev restèrent pendant six ans pour enseigner au monastère de la Trinité; d'habitude, un enseignant ne restait pas plus de trois ou quatre ans. Dans les meilleurs établissements, l'enseignement des langues modernes n'était pas interrompu, mais pour autant, sa qualité était inégale.

\section{Les élèves}

Du fait que les cours de langues, pendant tout le XVIII ${ }^{\mathrm{e}}$ siècle, étaient "extraordinaires," c'est-à-dire facultatifs et destinés seulement aux élèves en fin de cursus (qui étaient généralement bien moins nombreux que ceux des premières années), leur nombre ne pouvait pas être bien grand. Le tableau suivant donne une idée du nombre d'élèves dans les cours de langue des séminaires de province.

Tableau 2. Nombre d'élèves apprenant une langue étrangère dans les séminaires de province ${ }^{97}$

\begin{tabular}{|l|l|l|}
\hline & Allemand & Français \\
\hline Séminaire de Riazan & & $\begin{array}{l}1771-13 \text { personnes (7 élèves du cours } \\
\text { de versification, 2 du cours de } \\
\text { rhétorique et 4 de celui de } \\
\text { philosophie) }\end{array}$ \\
\hline & & $\begin{array}{l}1776 \text { - } 16 \text { personnes (7 élèves du cours } \\
\text { de versification, 2 du cours de }\end{array}$ \\
\hline
\end{tabular}

95 RGADA, fonds 1204, op. 1, d. 985, f 2-2 $v$. 96 RGADA, fonds 1204, op. 1, d. $985, \mathrm{f}^{\circ} 3 v$. 97 Etabli d'après: Агнцев, Рязанская семинария, 119; Князев, Псковская семинария, 27; Колосов, Тверская семинария, 226; Макарий, Киевская академия, 155; Николаев, Списки воспитанников, 17, 18, 21, 40; Сперанский, Очерк истории Смоленской духовной семинарии, 11о; Шмурло, Митрополит Евгений, 101. 


\begin{tabular}{|l|l|l|}
\hline & & $\begin{array}{l}\text { rhétorique, 4 de celui de philosophie, } \\
3 \text { du cours de théologie) }\end{array}$ \\
\hline Séminaire de Pskov & $\begin{array}{l}1774-12 \text { élèves du cours de } \\
\text { rhétorique }\end{array}$ & \\
\hline Séminaire de Tver & $1778-38$ personnes & \\
\hline Séminaire de Voronej & $1789-18$ personnes & \\
\hline & $1790-10$ personnes & \\
\hline & $1792-27$ personnes & \\
\hline & $1798-29$ personnes & \\
\hline Académie de Kiev & $1798-136$ personnes & \\
\hline & $1803-211$ personnes & \\
\hline Séminaire de Smolensk & $1811-125$ personnes & \\
\hline
\end{tabular}

Les élèves inscrits n'étaient pas tous assidus. Par exemple, dans le séminaire de Riazan, en 1810, l'archevêque Théophilacte (Féodor Roussanov, 1765-1821) exigeait de chaque élève de philosophie et de théologie qu'il apprît au moins une langue moderne. En septembre et octobre 1810, 40 élèves de théologie et 51 de philosophie furent inscrits au cours d'allemand et de français, mais seuls 21 élèves de théologie et 30 de philosophie assistèrent aux cours. ${ }^{98}$

Les données du séminaire de la Trinité permettent de dresser le tableau le plus de détaillé. Lors de l'introduction des cours de langue en 1763, 15 grammaires de français et d'allemand furent commandées à l'Académie des sciences. En 1767, sur ordre de Platon, 20 élèves sont inscrits au cours de français. ${ }^{99}$

Tableau 3. Nombre d'élèves par classes au séminaire de la Trinité ${ }^{100}$

\begin{tabular}{|l|l|l|l|l|}
\hline & $\begin{array}{l}\text { Elèves de } \\
\text { théologie }\end{array}$ & $\begin{array}{l}\text { Elèves de } \\
\text { philosophie }\end{array}$ & $\begin{array}{l}\text { Elèves de } \\
\text { rhétorique }\end{array}$ & $\begin{array}{l}\text { Elèves de } \\
\text { versification }\end{array}$ \\
\hline $\begin{array}{l}\text { Novembre 1763- } \\
\text { allemand, au } \\
\text { total, 16 }\end{array}$ & 3 & 5 & 2 & 6 \\
\hline $\begin{array}{l}\text { Novembre 1763- } \\
\text { français, au total, } \\
15\end{array}$ & 4 & 1 & 2 & 8 \\
\hline $\begin{array}{l}1765- \\
\text { allemand, selon le } \\
\text { registre, "au total, } \\
18, " \text { en réalité, 19 }\end{array}$ & 8 (sur 24) & 5 (sur 20) & 6 (sur 39) & \\
\hline $1765-$ & 7 (sur 24) & 5 (sur 20) & 13 (sur 39) & \\
\hline
\end{tabular}

98 Агнцев, Рязанская семинария, 121.

99 Смирнов, Троицкая семинария, 348.

100 RGADA, fonds 1204, ор. 1, d. 180, fo 5-11, 15; Смирнов, Троицкая семинария, 348.

101 Dans le registre manuscrit, les chiffres ont été corrigés: pour l'allemand et les élèves de théologie, le chiffre 7 a été corrigé en 8 , en rhétorique, 8 est corrigé en 6 , le total de 18 , lui, n'a pas été corrigé; pour le français et les élèves en théologie, 6 a été corrigé en 7 , en rhétorique, 10, mais 13 est inscrit au crayon à mine, le total de 18 est corrigé en 22. La différence des chiffres est liée aux registres dans lesquels les notes des élèves étaient mentionnées au départ, puis rayées (pour le français, Mikhaïlo a une note rayée "plutôt réussi" (nekhoudo ouspel), Alexeï Patokine a "bien” (prilejno), Petr Ponomarev a "excellent" (preizriadno oboutchalsia), etc.). Les notes sont rayées pour les élèves qui connaissaient bien le français - voir Ю. К. Бегунов, "Сусальников Михаил Иванович”; “Пономарев Петр Николаевич,” Словарь русских писателей XVIII века, vol. 3 (C-Я) (С.-Петербург: Наука, 2010). Il est impossible d'expliquer la raison de ces différences. 
français, selon le registre "au total, 22," en réalité, 25

S. Smirnov fournit également les données sur le nombre d'élèves des différents cours du séminaire de la Trinité à l'époque de Platon (Levchine), nous ne citerons que ceux qui permettent de comparer le nombre d'élèves en français et en allemand par rapport au total des étudiants du séminaire.

Tableau 4. Nombre d'élèves étudiant les langues étrangères au séminaire de la Trinité

\begin{tabular}{|l|l|l|l|}
\hline & Français & Allemand & $\begin{array}{l}\text { Total des étudiants } \\
(100 \%)\end{array}$ \\
\hline 1776 & $40(19 \%)$ & $12(6 \%)$ & 214 \\
\hline 1777 & $41(20 \%)$ & $26(13 \%)$ & 201 \\
\hline 1778 & $51(22 \%)$ & $42(18 \%)$ & 232 \\
\hline 1783 & $64(27 \%)$ & $75(32 \%)$ & 235 \\
\hline 1785 & $67(35 \%)$ & $55(29 \%)$ & 191 \\
\hline 1788 & $55(20 \%)$ & $39(14 \%)$ & 272 \\
\hline 1790 & $61(18 \%)$ & $39(11 \%)$ & 338 \\
\hline 1792 & $59(20 \%)$ & $58(19 \%)$ & 301 \\
\hline 1794 & Fermé & $46(14 \%)$ & 336 \\
\hline 1796 & Fermé & $45(14 \%)$ & 327 \\
\hline 1797 & Fermé & $48(20 \%)$ & 243 \\
\hline 1798 & $48(18 \%)$ & $51(19 \%)$ & 263 \\
\hline 1800 & $46(17 \%)$ & $37(14 \%)$ & 264 \\
\hline 1804 & $135(38 \%)$ & $67(19 \%)$ & 351 \\
\hline 1809 & $94(36 \%)$ & $50(19 \%)$ & 258 \\
\hline 1811 & $71(26 \%)$ & $46(17 \%)$ & 268 \\
\hline
\end{tabular}

Y-a-t-il une corrélation entre le choix d'une langue européenne et celui d'une langue "théologique" ? ${ }^{103} \mathrm{Si}$ l'on se base sur les informations à notre disposition pour le séminaire de la Trinité, pour l'année 1765 , on peut parler d'un lien direct entre l'étude de l'hébreu et celle de l'allemand: cinq étudiants de théologie et un de philosophie étudiaient en plus le grec; trois étudiants de théologie et un de philosophie étudiaient le français en plus de ces deux langues. Vraisemblablement, la raison de cette combinaison de langues réside dans la dominante protestante du milieu culturel. A cette époque, l'hébreu était fortement représenté dans les universités allemandes protestantes. C'est justement là qu'étudièrent certains enseignants russes d'hébreu (Simon Todorski, Konstantin Krijanovski, Ivan Naoumov, Vassili Antonski).

5. Méthodes d'enseignement des langues, manuels scolaires et résultats obtenus.

La méthode d'enseignement utilisée dans les établissements religieux était principalement l'apprentissage par cœur et la traduction depuis et vers le russe (Antoine Orénove employait aussi la version latine: “[...] il dictait à ses élèves l'histoire de la Russie en latin et ses étudiants traduisaient sur le champ en français et en allemand; il leur apprenait 
la géographie de la même façon”). ${ }^{104}$ Les enseignants utilisaient les grammaires et les œuvres choisies publiées à l'étranger et en Russie (par l'Académie des sciences et l'université de Moscou), également utilisées dans les établissements laïques: ${ }^{105}$ les plus populaires étaient les grammaires du français de J.P. Peplier et de M.N. Sokolovski, ${ }^{106}$ les grammaires allemandes de Franz Hoelterhof et Johann Christoph Gottsched. ${ }^{107}$ La particularité de l'enseignement religieux transparaît partiellement dans les textes choisis pour la lecture et la traduction: les enseignants étudiaient avec leurs élèves les prédications, lisaient les Saintes Ecritures et les œuvres religieuses étrangères. ${ }^{108}$ Les textes les plus couramment utilisés pour traduire du français étaient les Aventures de Télémaque de Fénelon, et pour l'allemand, les Lettres de Christian Fürchtegott Gellert, ${ }^{109}$ on lisait aussi en allemand les œuvres de A.M. Arndt, de F.G. Klopchtok et de G.E. Lessing, et en français celles de J.-B. Bossuet et de J.-B. Massillon.

Tout comme dans les établissements laïques, la méthode d'enseignement consistait à traduire des livres. ${ }^{110}$ Les étudiants de théologie du séminaire de Voronej, par exemple, traduisaient Les erreurs de Voltaire, de Claude François Nonnotte ${ }^{111}$ (édité à Moscou en 1793, existant aussi sous forme de copies manuscrites), dont Evgeni (Bolkhovitinov) fut le relecteur. ${ }^{112}$ Le métropolite Platon (Levchine) établit un poste de traducteur au séminaire de la Trinité. ${ }^{113}$ Une série de traductions furent réalisées par les enseignants et les élèves du séminaire. Bien que les traductions du latin dominent, de nombreux ouvrages furent également traduits du français et de l'allemand. ${ }^{114}$

104 Смирнов, Троццкая семинария, 352.

105 Voir: Вержболович, Минская семинария, 62; Вишневский, Киевская академия, 272; Князев, Псковская семинария, 41; Макарий, Киевская академия, 155-156; Смирнов, Троицкая семинария, 348, 349-350; Смирнов, Московская академия, 310; Сперанский, Очерк истории Смоленской духовной семинарии, 110; Чистович, Санкт-Петербургская академия, 114.

106 J.-R. Des Pepliers, Grammaire Royale Françoise et Allemande, contenant une Methode nouvelle et façile [sic !] pour apprendre en peu de temps la langue françoise, Avec une Nomenclature, des Dialogues nouveaux, Bouquet des Sentences, des Lettres et billets galants de ce temps, ecrite par Mr Jean Robert des Pêpliers, Informateur de Monseig. Le Duc de Bourgogne... (В.: [...], 1689); М. Н. Соколовский, Сокращенная французская грамматика: Расположенная по вопросам и ответам, С российским переводом вновь исправлена с прибавлением сочинения частей слова Мартыном Соколовским ([Москва]: Печ. при Имп. Моск. ун-те, 1770) et d'autres éditions.

107 Ф. Гельтергоф, Немецкая грамматика: В которой не токмо все части речи или произведение слов, но и синтаксис или сочинение слов, оба надлежащими примерами объяснены (Москва: [Унив. тип.], 1784); Готшедова немецкая грамматика, вновь исправленная и для пользы и употребления российского благородного юношества напечатанная 2-м тиснением (С.-Петербург: При Морск. шляхетн. кад. корпусе, 1769).

108 Смирнов, Троицкая семинария, 354-355.

109 F. Fénelon, Les Aventures de Télémaque (nombreuses rééditions); C. F. Gellert, Briefe, nebst einer praktischen Abhandlung von dem Geschmacke in Briefen (Leipzig: Verlest Caspar Fritsch, 1751).

110 Ю. Д. Левин, История русской переводной художественной литературы. Древняя Русь. ХVIII век, t. 1. Проза (С.-Петербург: Издательство Дмитрия Буланина, 1995), 148-150.

111 Claude François Nonnotte, Les Erreurs de Voltaire (A Paris, et se vend à Avignon, chez Antoine-Ignace Fez, 1762), 2 vol., la traduction russe: Клод Франсуа Ноннот, Волтеровы заблуждения, Обнаруженныя аббатом Нонотом; Переведена с французскаго оригинала последняго шестаго издания в Воронежской семинарии студентами богословии (Москва: Тип. М.Пономарева, 1793).

112 Voir: Шмурло, Митрополит Евгений, 127-134.

113 Смирнов, Троицкая семинария, 357-359.

114 Списки переводов, выполненных в семинариях: Смирнов, Троицкая семинария, 374-376; Смирнов, Московская академия, 335-337; Чистович, Санкт-Петербургская академия, 91-93; Шмурло, Митрополит Евгений, 59-85, 125-137, еtс. 
On accordait une importance particulière à la conversation, ${ }^{115}$ au point parfois d'obliger les élèves à parler entre eux les langues étrangères "dans l'école et dans les dortoirs." Néanmoins, le manque de pratique se faisait sentir, et dans les mémoires de leurs contemporains, les séminaristes se démarquaient par leur "mauvaise prononciation" en dépit d'un bon niveau à l'écrit. ${ }^{116}$

Dans la deuxième moitié du XVIII ${ }^{\mathrm{e}}$ siècle, le français pouvait s'immiscer dans la vie quotidienne du clergé, remplaçant partiellement le "latin savant," répandu dans la correspondance officielle et personnelle de ses membres. La lettre de Petr (Paul) Zernov au métropolite Platon (1766), où il lui annonça son désir d'entrer dans les ordres, en offre un bon exemple:

Monseigneur! Comme il n'y a personne, qui vous estime plus, que moi, croyez aussi, qu'il n'y a personne, qui plus volontiers exécute votre volonté. Je veux temoigner par des effets plutot, que par mes paroles. Cette lettre, que j'ai l'honneur à vous ècrire, vous assurera de cette verité. Quoique je n'ai jamais eu l'intention d'être le moine, monseigneur, mais si vous voulez, si comandez de l'être, j'y consens et vous obéis, pour vous témoigner, jusqu'à quel point j'estime l'honneur de vos commandemens. Disposez donc de moi à votre plaisir, je me soumets en toutes choses à la volonté de votre grandeur. Je ne pouvois omettre une occasion si opportune [...] preuves de mon obéissance. ${ }^{117}$

On sait que Zernov se refusa longtemps à prendre les ordres et n'accepta que sous une pression certaine du métropolite Platon. Le choix de la langue, ici, vient peut-être du souhait de souligner l'écart entre le souhait réel de Zernov et ce qu'il s'apprêtait à accomplir.

Mais le goût pour les langues européennes n'était pas partagé dans tous les établissements. Par exemple, au séminaire de Riazan, personne ne souhaitait étudier les langues: en septembre 1798, sur deux classes (grande et petite de grammaire), seul un élève étudiait les langues étrangères; Alexei Roubetski déclara vouloir apprendre l'allemand, cependant, "du fait de sa pauvreté, comme il l'a dit lui-même, il ne peut pas acheter les livres allemands demandés"; ${ }^{118}$ sur les recommandations insistantes de la direction du séminaire, le 17 novembre, neuf élèves de la classe de rhétorique et quinze de la grande classe de grammaire, s'inscrivirent au cours d'allemand. Mais les élèves inscrits refusèrent d'assister au cours. Dans le registre du $1{ }^{\text {er }}$ trimestre ("de janvier") 1792, il fut inscrit que "l'enseignant d'allemand et de français a souvent été absent du consistoire et pour le français, n'a pas fait cours depuis le nouvel an, du fait que les élèves n'ont pas souhaité y assister"; au trimestre de mai, un cours de français eut lieu et à celui de septembre, le professeur d'allemand fut absent plusieurs fois car les élèves furent allés aux bains, et il n'y eut pas de cours de français depuis les vacances car les élèves se refusaient à aller en cours. Le révérend Simon (Stefan Lagov, 1720-1804) menaça les élèves de ne pas les libérer avant qu'ils eussent maîtrisé ces deux langues, mais la menace resta sans effet, pas plus que les amendes infligées à l'enseignant. M. Protopopov, enseignant, avança comme raison du faible niveau

\footnotetext{
115 Чистович, Санкт-Петербургская академия, 114-115; Сперанский, Очерк истории Смоленской духовной семинарии, 110; Смирнов, Троицкая семинария, 353, еtс.

116 Voir: Любжин, Очерки, 18-19.

117 Смирнов, Троицкая семинария, 145-146.

118 Агнцев, Рязанская семинария, 120.
} 
d'apprentissage, "l'absence de grammaires allemandes," ce qui rendait impossible l'apprentissage de la langue après l'acquisition des rudiments pour la lecture et l'écriture. ${ }^{119}$

Lorsque les séminaires se préoccupaient de la politique d'acquisition des bibliothèques, le matériel pédagogique se trouvait en nombre suffisant. En témoigne la bibliothèque du séminaire de Smolensk, qui détenait 40 livres en allemand et 39 en français (pour un total de 2000 livres); ${ }^{120}$ l'évêque Damaskine (Sémionov-Roudnev) commanda personnellement des livres en allemand pour la bibliothèque du séminaire de Nijni Novgorod. ${ }^{121}$ Vers 1800 , la bibliothèque de Voronej comptait plus de 5000 titres et fut alimentée par les soins d'Evgueni (Bolkhovitinov): "En 1792, envoyé par l'évêque Innokenti, il se rendit à Moscou spécialement pour acheter des livres, et un an plus tard, il demanda la somme nécessaire à l'acquisition de livres comme l'Encyclopédie française, le dictionnaire de Bayle, les œuvres de Voltaire, etc." 122

Lorsque les circonstances étaient favorables (supposant la présence concomitante de bons instituteurs, de bons manuels et de bonnes grammaires), les séminaristes arrivaient à un degré de maîtrise du français et de l'allemand qui leur permettait d'écrire leurs propres œuvres dans ces langues en respectant toutes les règles de la rhétorique et de la poétique. L'un de principaux moyens de démontrer ses connaissances étaient les "actes" du séminaire, pendant lesquels les élèves, en public, lisaient des vers et prononçaient des discours en langues étrangères. ${ }^{123}$ Les œuvres composées à cette occasion étaient consignées dans des manuscrits ou éditées et présentées en hommage aux archevêques responsables du diocèse ou aux visiteurs éminents, l'impératrice, l'héritier du trône, etc. On peut trouver beaucoup de documents de ce genre dans les archives. Voici quelques exemples qui témoignent à la fois de la diversité des genres pratiqués - épigramme, vers pour une occasion particulière, discours solennels, etc. - et du haut degré de maîtrise du français qu'avaient ces élèves de séminaire ou d'académie ecclésiastique. Ainsi, les vers "pour une occasion particulière":

Aux accens, dont Orphee remplit les mons de Thrace,

Les tigres amollis depou(i)llo(i)ent ${ }^{124}$ leur audace;

Aux accords d'Amphion les pierres se mouvoient,

Et sur les murs Thebains en ordre s'élevoient.

Mais Platon produit plus par sa grande eloquence,

Aux passions des humains il impose le silence,

Il tarit toutes les sources, où commence l'erreur,

En deployant les Cieux il nous montre notre bonheur.

Etud. en Theol. Jean Platonow ${ }^{125}$

Les épigrammes versifiées étaient aussi monnaie courante:

119 Агнцев, Рязанская семинария, 120-121.

120 Voir Сперанский, Очерк истории Смоленской духовной семинарии, 113-114.

121 Горожанский, Дамаскин, 234.

122 Шмурло, Митрополит Евгений, 106.

123 Pour la description des fêtes et des actes solennels, voir: Агнцев, Рязанская семинария, 147-158; Чистович, Санкт-Петербургккая семинария, 24; Знаменский, Духовные школы, 478, и др.

124 Il était écrit "depoulloent," le i est ajouté de la même main avec la même encre entre les lettres au-dessus du mot.

125 RGB, Mss, fonds 173, op. III, d. 131, f f $^{\circ}$. Innokenti (Ivan Vassilievitch) Platonov (vers 1773-1842) a été recteur de l'institut ecclésiastique Zaikonospasski, du séminaire de Penza, archimandrite du monastère Bogoiavlenski (de l'Epiphanie) de Moscou, professeur de théologie à l'université de Moscou, et l'auteur d'une grammaire latine et grecque (Свод латинской грамматики с греческой, или грамматика латиногреческая, 1826). 
Durera pour jamais la renommée des sages;

Or celle de Platon vaincra bien tous les ages.

Etud. en Theol. Basile Czeredeew ${ }^{126}$

Les discours solennels étaient le genre le plus répandu:

Tres Auguste Souveraine!

Au milieu du peuple, qui accourt en foule sur les pas de VOTRE MAIESTE IMPERIALE, pour exprimer, par des exclamations réiterés, les sentiments de sa joie \& admirer en ELLE, les vertus qui assurent son repos, vient renouveller dans cette jeunesse le plus delicieux spectacle pour une ame tendre et sensible. Ah! Qu'il est doux d'envisager les grands Princes, qui tout élévés qu'ils sont, ne se lassent pas cependant de descendre iusqu'à leurs sujets qui les cherissent! Oui! Ces sentiments, nous charment et nous enyvrent! Nous le voions, nous le sentons dans cet heureux moment! Puisse ma foible voix être auprès de VOTRE MAIESTE IMPERIALE interprete de la profonde soumission, que nous LUI devons, de meme que de notre vive reconnaissance de la gracieuse presence, dont ELLE, a bien voulu nous honorer. ${ }^{127}$

D’habitude, les textes de ce genre pour des événements solennels étaient écrits par les meilleurs élèves; leur niveau peut être considéré comme très bon. Le plus souvent, les textes en français et en allemand accompagnaient d'autres vers et discours en russe, latin, grec, et dans de rares cas, de brèves épigrammes en hébreu. Parfois, on montrait aux hôtes sa maîtrise d'une langue rare: le carélien, le tatare, le kalmouk. La composition littéraire en langue étrangère devint, de cette façon, un moyen de faire la démonstration de l'éducation reçue. Les hôtes pouvaient ne pas la comprendre, on ne le leur demandait pas: les étudiants montraient leur connaissance d'une langue comme un signe extérieur d'éducation. De ce point de vue, les textes en allemand et en français présentaient l'avantage d'être plus facilement compris du public issu de la société civile, comparés aux œuvres en latin, en hébreu ou en carélien. La poésie et les discours en langues étrangères composés dans les séminaires n'ont pas fait l'objet d'études approfondies à ce jour.

6. Objectifs poursuivis par l'introduction du français et de l'allemand dans l'enseignement religieux. Attitude du clergé vis à vis de ces langues

Qu'est-ce qui motivait l'introduction du français et de l'allemand dans les programmes des séminaires? Peut-on considérer qu'il s'agit d'un moyen de défendre la foi orthodoxe? Cette interprétation semble évidente, cependant, dans les documents que nous avons pu voir, rien ne prouve qu'au XVIII ${ }^{\mathrm{e}}$ siècle, les représentants de l'Eglise considéraient les langues européennes comme un moyen de lutte contre le protestantisme et le

126 RGB, Mss, fonds 173, op. III, $d .131, \mathrm{f}^{\circ}$ 47. Nous n'avons malheureusement pu trouver aucune information sur Basile Czeredeew.

127 Стихи, речи и канты на всерадостное в Тверь прибытие великия государыни Екатерины Вторыя, императрицы и самодержицы всероссийския. 177[5] года, [генваря 2о] дня ([М.]: [Унив. тип.], 1775), [6]. Il est intéressant de noter que nous avons trouvé, au musée du livre de la Bibliothèque d'Etat russe (RGB), un exemplaire avec le texte du discours annoté en russe dans la marge, mais aussi avec la transcription en caractères cyrilliques du texte français “О мильјо дю пјопль ки акур тан фуль сюр ле па д вотръ мажестъ империаль [...].” Cela peut vouloir dire que ce genre de textes était utilisé pour l'apprentissage. D'autres textes de ce recueil ne portent aucune annotation de ce genre. 
catholicisme. ${ }^{128}$ Dans la deuxième moitié du siècle, le principal ennemi de l'Eglise étaient les tendances athéistes et le voltairianisme de la société. On peut également considérer que le renforcement de l'enseignement des langues était un moyen de contrer l'engouement, dans les hautes sphères de la société, pour les mysticismes et les idées maçonniques: pour faire figure d'autorité dans ce milieu, le hiérarque orthodoxe se devait de connaître, outre les Ecritures Saintes, la langue de ses "ennemis idéologiques." Afin de combattre certaines dispositions d'esprit, il fallait bien les connaître. C'est pour cette raison que l'on recueillait activement dans les séminaires tout ce qui fut publié dans le domaine de la religion en France et en Allemagne, que l'on commandait des livres, qu'on les traduisait: les clergés français et allemands étaient regardés non pas comme des opposants idéologiques, en tant que protestants ou catholiques, mais comme des alliés dans la lutte contre l'athéisme.

Mais la raison fondamentale de l'introduction du français et de l'allemand pouvait aussi être surtout la nécessité de lutter contre l'image persistante d'un clergé "illettré." La connaissance des langues importante dans la culture civile permettait à l'Eglise orthodoxe de dépasser l'image qui a commencé de se former après les réformes de Pierre le Grand et qui perdurait dans la deuxième moitié du XVIII ${ }^{\mathrm{e}}$ siècle: pendant tout ce siècle, en effet, les préambules de presque tous les oukases et dispositions du gouvernement consacrés à l'enseignement religieux faisaient une tradition de souligner le faible niveau d'éducation et le retard du clergé, ainsi que la faiblesse de l'enseignement dans les séminaires. A ce titre, les témoignages des étrangers sur les religieux russes sont significatifs. C'est ainsi que Vockerodt décrit l'époque pétrovienne:

Après l'introduction du nouveau Règlement spirituel et la mise en place des institutions qui y étaient associées, Pierre $\mathrm{I}^{\mathrm{er}}$ ne voulait rien de plus que tirer son clergé de sa précédente ignorance. Celui-ci était au début de son règne de loin plus grossier que ne l'était le clergé en Europe dans les siècles les plus sombres de la papauté. [...] Ceux qui savaient lire et écrire et observer les cérémonies de l'Eglise, avaient toutes les qualités nécessaires pour remplir les places non seulement de prêtres, mais même d'évêques. Si quelqu'un avait la réputation de mener une vie morale et avait de nature une barbe abondante, il passait pour un ecclésiastique exceptionnel. ${ }^{129}$

Les dignitaires de l'Eglise russe n'ignoraient pas qu'on les jugeait ainsi: le métropolite Platon (Levchine) écrivait, en 1801: "Nos religieux déjà considérés par les étrangers comme

128 Ju. K. Vorobiev et I. V. Sedina écrivent: “En 1747, l'archevêque de Smolensk, Gédéon (Vichnevski) émit l'opinion que pour combattre le catholicisme [c'est moi qui met en italique - E.K.], il faut créer des écoles à Smolensk, enseigner le latin, le français et l'allemand, et pour ceux qui veulent devenir prêtres, le grec" (Воробьев и Седина, Западноевропейские языки, 88). En réalité, cette citation de vient pas de Gédéon, elle se trouve dans l'oukase personnel de Pierre II et il n'y est nullement question de lutte contre le catholicisme. Cette fausse référence se retrouve aussi dans le Dictionnaire biographique russe de Polovtsov (А. А. Половцов (dir.), Русский биографический словарь, t. IV. Гааг - Гербель (Москва: Типография Г. Лисснера и Д. Совко, 1914), 321).

129 "Nächst der Einführung dieser neuen geistlichen Reglementsform, und der damit verknüpften Anstalten, hat Petrus I. sich nichts mehr angelegen sein lassen, als seine Clerisei aus der vorigen Unwissenheit zu ziehen. Dieselbe war zu Anfang seiner Regierung weit gröber, als sie in Europa in den finstersten Seculis des Pabstthums gewesen sein kann [...] Wer lesen und schreiben konnte, und die Ceremonien der Kirche genau zu beobachten wusste, der hatte alle Requisita, die man nicht nur zu einem Priester, sondern auch zu einem Bischof erforderte. Konnte er sich dabei in Reputation eines strengen Lebens setzen und war von Natur mit einem weitschichtigen Bart begabet, so passirte er vor einen ausnehmenden Geistlichen.” E. Herrmann (Hrsg), Russland unter Peter dem Grossen. Nach den handschriftlichen Berichten Johann Gotthilf Vockerodt's und Otto Pleyer's (Leigzig: Verlag von Duncker \& Humblot, 1872), 14-15. 
quasiment incultes, ne peuvent parler ni le français, ni l'allemand. Notre honneur est encore sauf grâce au fait que nous parlons et correspondons en latin." ${ }^{\text {zo }}$

De fait, avant Pierre $\mathrm{I}^{\mathrm{er}}$, dans la Russie centrale, l'enseignement des religieux se faisait surtout à domicile: les enfants de prêtres apprenaient de leurs pères le règlement de l'Eglise, la pratique liturgique et le slavon d'Eglise:

Toute l'éducation que les pères réussissaient à donner pendant leur temps libre se résumait à apprendre à lire le slavon et à recopier en écriture slavonne stricte ou régulière. Quand [...] l'alphabet fut appris, [...] on passait à la lecture des psaumes et d'autres livres religieux. ${ }^{131}$

Ce modèle d'enseignement répondait aux besoins de la population, mais du point de vue des modèles d'éducation européens répandus dans la partie occidentale de l'Empire russe, les prêtres qui ne savaient que lire et dire la messe étaient vus comme "des illettrés," incapables de prononcer une prédication ou d'instruire leurs ouailles. La société civile de la première moitié du XVIII ${ }^{\mathrm{e}}$ siècle associait le fait d'être éduqué et lettré, à un apprentissage systématique "à l'occidentale," dans un collège, une académie ou une université; au début du $\mathrm{XVIII}^{\mathrm{e}}$, la connaissance du latin était un exemple remarquable d'un homme cultivé, mais à la fin du même siècle, lorsque le latin était déjà répandu dans les séminaires, la société portait son attention sur le français et l'allemand.

Pendant longtemps, la connaissance de langues européennes constituait le signe qui distinguait un prêtre ou un religieux instruit. F.B. Bergholtz écrivait à propos de Théophile Krolik (mort en 1732): "Parmi eux se trouvaient des gens polis et cultivés [...] aussi quelqu'un du nom de Crolli, qui parlait beaucoup de langues et aussi l'allemand assez couramment." 132 Dans la biographie du métropolite Gavriil (Petrov), dès les premières lignes, on précise qu'il "[...] fut un des prélats les plus éloquents et les plus instruits de l'église russienne. Il savait non-seulement le grec et le latin, mais il parlait avec facilité plusieurs langues européennes" (mes italiques - E.K.). ${ }^{133}$

Dans la société civile, maîtriser le français, et dans une moindre mesure, l'allemand, n'était pas seulement synonyme d'éducation, mais aussi de cette distinction que l'on refusait a priori d'attribuer aux représentants du clergé. Ce que Karamzine écrit de sa visite au monastère de la Trinité Saint-Serge en 1802 et des échanges qu'il y entretint avec les moines est caractéristique:

130 Смирнов, Троицкая семинария, 340-341.

131 "Все домашнее обучение, какое удавалось отцам произвести в свободное от работы время, по большей части сводилось к одному только уменью читать церковную азбуку и переписывать ее уставом или полууставом. Когда [...] осиливалась наконец азбука [...] приступали к чтению псалтыри и других церковных книг." М. Побединский, Старинные Томские духовные школы (1746-1820 г2.) (Томск: Паровая типо-литография П. И. Макушина, 1896), 3-4; voir aussi Знаменский, Духовные школы, 348; А. Г. Кравецкий, “Литургический язык как предмет этнографии,” in Е. Е. Левкиевская (dir.), Славянские этюды. Сборник к юбилею С. М. Толстой (Москва, 1999), 228-242 (230-231).

132 "Unter ihnen find einige recht artige und gelehrte leute [...] auch einer mit Namen Crolli, der viele Sprachen und auch die deutsche ziemlich fertig spricht [mes italiques - E.K.]," in "Tagebuch, welches der großfürstliche Oberkammerherr Friedrich Wilhelm von Bergholz, als holsteinischer Kammerjunker und Kammerherr, von 1721 bis 1725 in Rußland geführet hat," Vierter Theil, von 1724. S. 425-506 (506), in Magazin für die neue Historie und Geographie. B. 22 (Halle: Verlegt von sel. Johann Jacob Curts Bitwe, 1788).

133 L.-G. Michaud (dir.), Biographie universelle, ancienne et moderne. Supplément, ou suite de l'histoire, par ordre alphabétiquie, de la vie publique et privée de tous les hommes qui se sont fait remarquer par leurs écrits, leurs actions, leurs talents, leurs vertus ou leurs crimes, t. 65 (Paris: Chez L.-G. Michaud, Libraire-Éditeur, 1838), 5-6. 
En dehors des langues anciennes, on apprend ici le français et l'allemand. C'est louable: celui qui veut prédiquer doit connaître Bossuet et Massillon. Certains des moines d'ici ont parlé français avec moi, tandis que les enseignants principaux introduisaient des phrases françaises dans leur conversation. Ils m'ont démontré que la connaissance est affable: ils m'accompagnaient et me montraient tout avec un air de sincère déférence. La science donne à l'homme une certaine distinction, quel que soit son état. ${ }^{134}$

On voit formulées ici les principales représentations que se faisait la société civile sur le clergé: 1) les prédicateurs doivent connaître les principaux rhéteurs reconnus par la société; 2) la connaissance est bénéfique, c'est-à-dire, la connaissance du français équivaut de facto à une bonne éducation, à la politesse et à la déférence; 3) la connaissance du français est, de fait, mise sur un pied d'égalité avec la science, puisque dans l'esprit de Karamzine, cette langue est "la clé de la connaissance," laquelle à son tour, confère la distinction au clergé.

Cette image n'a pu se former que dans un contexte de séparation entre le clergé et la noblesse, ce dont témoignent les mémoires de l'époque:

[...] Durant les cinq mois que nous passâmes à Saint-Pétersbourg, et dans nos échanges quotidiens avec la noblesse, pas une fois n'ai-je vu un représentant de l'Église au sein d'une société. Il faut reconnaître, en effet, que les prêtres de paroisse sont, pour la plupart, trop bas et ignorants pour pouvoir être admis dans la bonne société; alors que les dignitaires de l'Eglise, qui appartiennent à un ordre séparé et sont soumis à des règles strictes, vivent principalement dans leurs palais, au milieu des monastères, et contractent une aversion, peut-être une inadéquation, pour les relations sociales. ${ }^{135}$

\section{E. P. Iankova dit à peu près la même chose, sans le juger négativement:}

A l'époque [au début du XIX ${ }^{\mathrm{e}}$ siècle - E.K.], on rendait rarement visite aux évêques: ou bien ils étaient eux-mêmes très peu accessibles, ou bien les gens du monde ne s'empressaient pas de se fourrer dans leurs maisons, toujours est-il qu'ils y allaient peu et ne les importunaient pas comme on se mit à le faire à Moscou par la suite. Les évêques non plus ne rendaient pas tellement visite à notre compagnie, sauf pour voir certains dignitaires de la ville ou bien quelques personnes haut placées en particulier. Mais, dans les provinces, les évêques avaient des échanges surtout avec la noblesse $[\ldots] .{ }^{136}$

134 “Кроме древних языков, здесь учат французскому и немецкому. Это похвально: кому надобно проповедывать, тот должен знать Боссюэта и Массильйона. Некоторые из здешних монахов говорили со мною по-французски, а важные учители вмешивали в свой разговор французские фразы. Они доказывали мне, что ученость приветлива: ходили со мною и все показывали с видом искренней услужливости. Наука дает человеку какое-то благородство во всяком состоянии.” Смирнов, Троицкая семинария, 483.

135 "[...] during the five months we passed at Petersburg, and in our daily intercourse with the nobility and gentry, I never once saw in company a single person of the sacred profession. It must be allowed, indeed, that the parish-priests are, for the most part, too low and ignorant to be qualified for admission into genteel societies; while the dignitaries, being a separate order, and restrained by strict regulations, reside chiefly in their palaces within the monasteries; and contract an aversion, perhaps an unfitness, for social intercourse." William Coxe, Travels into Poland, Russia, Sweden and Denmark, en 5 vol. (London: Printed for T.Cadell, in the Strand, 1802), vol. 3, 145 .

136 "В то время [в начале 19 в.] вообще как-то нечасто езжали к архиереям: сами ли они были чересчур недоступны, или светские люди не очень домогались втираться в дом к архиереям, только к ним мало 


\section{Conclusion}

La connaissance des langues était une opportunité de dépasser la division entre le clergé et la noblesse, de faire entrer les représentants de l'Eglise dans le cercle des gens instruits, aux yeux de la société civile: "La seule capacité à parler le français ou l'allemand leur donnait de l'importance dans la société et les élevait aux yeux de leurs pairs, et les gens cultivés les accueillaient avec bonheur dans leur société."137

L'ignorance du code linguistique de la société civile, au contraire, excluait le clergé de la culture de cette société, y compris de la cour, c'est pourquoi l'introduction du français et de l'allemand devenait cruciale dans les établissements dont sortaient les archimandrites des grands monastères, les archevêques et les métropolites, les membres du Saint Synode, les prédicateurs de la Cour, les enseignants de religion dans les établissements publics. Cette nécessité ressort bien dans la résolution sur l'introduction du français et de l'allemand au séminaire de la Trinité:

[...] parce qu'au séminaire de la Trinité, actuellement, on n'enseigne pas l'allemand et le français; du fait de la réputation de ce séminaire, et particulièrement parce qu'il a été institué par les oukases personnels de sa Majesté Impériale, qui lui fait parfois l'honneur de sa visite, et qu'il reçoit aussi des ministres étrangers et d'autres personnes de haut rang, pour cela il convient, pour la gloire et le bénéfice de la Patrie, de mettre en place l'enseignement de ces langues, le français et l'allemand, car elles sont les plus employées actuellement en Russie [...]. ${ }^{138}$

Pendant que le français devient la langue des échanges quotidiens au sein de la société civile, ${ }^{139}$ ce n'est qu'à la fin des années 1750 que l'Eglise passe d'un slavon hybride au russe pour ses sermons. ${ }^{140}$ À peu près au même moment se développent les "actes" (cérémonies) solennels avec "disputes" en latin, mais aussi en russe, événements très populaires auprès du public. Néanmoins, la langue de la théologie reste le latin ${ }^{141}$ la noblesse pour sa part ne comprend pas le slavon: "[...] la théologie et la littérature mystique étaient lues [par la

\footnotetext{
езжали и не докучали им, как потом это завелось в Москве [...] Да и архиереи мало посещали нашу братию, за исключением городских должностных сановников или каких-нибудь особенно сановных особ. Но в губерниях архиереи больше имели общения с дворянством [...].” Рассказы бабушки. Из воспоминаний пяти поколений, записанные и собранные ее внуком Д. Благово, е́d. Т. И. Орнатская (Москва: Либроком, 2013), 240.

137 Смирнов, Троицкая семинария, 465.

138 “[...] понеже в Троицкой семинарии ныне немецкого и французского языков никто не обучает; по знатности же оной семинарии, а особливо, что оная заведена по силе высочайших ея имп. величества именных указов, и удостоиваема бывает высочайшаго ея имп. величества посещения и зрения иностранных министров и других знатных персон, для того надлежит в прославление и пользу отечества присовокупить преподавание и оных двух языков французскаго и немецкаго, как больше ныне в России употребляемых [...]." Смирнов, Троицкая семинария, 347-348.

139 Гречаная, Когда Россия говорила по-французски, 13-14.

140 В. М. Живов, Очерки исторической морфологии русского языка XVII-XVIII веков (Москва: Языки славянской культуры, 2004), 574; Е. И. Кислова, “Проповедь 1740-х годов в истории русского языка,” in П. Е. Бухаркин, У. Екуч, Н. Д. Кочеткова (dir.), Окказиональная литература в контексте праздничной культуры России XVIII века (С.-Петербург: Филологический факультет СПбГУ, 2010), 33-52.

141 Voir К. В.Суториус, “Источники по истории преподавания православного латиноязычного богословия в России в первой половине XVIII века,” PhD diss. (С.-Петербургский институт истории Российской Академии наук, 2008). Il у eut plusieurs tentatives de traduire le cours de théologie en russe avant 1840, mais elles ne furent pas couronnées de succès. Voir Колосов, Тверская семинария, 174-175.
} 
noblesse] le plus souvent dans les langues européennes." ${ }^{142}$ Vers la fin du XVIII ${ }^{\mathrm{e}}$ siècle, la société civile ne considère plus la maîtrise virtuose du latin comme un signe quelconque d'instruction. ${ }^{143}$

Les représentants de l'Église comprenaient bien, manifestement, la nécessité de combler cette soudaine fracture. On remarquera qu'à côté de nombreuses protestations contre le renforcement de l'enseignement du russe dans les séminaires, les archives ne recèlent aucune plainte contre l'introduction du français ou de l'allemand. ${ }^{144}$

Ainsi, les informations présentées ici témoignent du fait qu'au XVIII ${ }^{\mathrm{e}}$ siècle, une partie des prêtres et des moines recevaient une éducation suffisamment solide dans les séminaires et acquéraient de bonnes connaissances en langues étrangères. L'une des preuves de ce bon niveau réside dans le fait qu'un grand nombre de savants, d'enseignants, de traducteurs et de fonctionnaires firent leurs études au séminaire et y apprirent les langues avant de partir occuper un poste, pour diverses raisons, dans la société civile: c'est le cas de M. M. Spéranski ayant étudié aux séminaires Saint-Vladimir et Alexandre Nevski, de N. I. Gnéditch, du séminaire de Poltava et du collège de Kharkov, devenu sénateur et écrivain-ethnographe, de l'historien S. V. Roussov, des séminaires de Kalouga et de la Trinité, du sinologue A. G. Vladykine, du séminaire de la Trinité, de S. E. Desnitski, professeur à l'université de Moscou, de N. Ja. Ozeretskovski, savant en sciences naturelles à l'université et académicien, de F. F. Rozanov, écrivain-traducteur et directeur de l'Imprimerie de Moscou, de N. P. Sokolov, ethnographe, écrivain et traducteur, pour ne citer qu'eux.

Bien entendu, ce n'était pas un phénomène de masse, et le niveau d'éducation des meilleurs élèves du séminaire de la Trinité différait grandement de celui des meilleurs élèves de pauvres séminaires du fin fond des provinces. Néanmoins, la situation réelle du clergé au $\mathrm{XVIII}^{\mathrm{e}}$ siècle était bien loin de l'image de gens quasiment incultes qui se forgea à cette époque et qui perdura jusqu'au $\mathrm{XX}^{\mathrm{e}}$ siècle.

142 Кравецкий, Литургический язык, 229-230.

143 Воробьев и Седина, Западноевропейские языки, 17-29.

144 La seule exception notable est la protestation d'Arséni Matseevitch contre l'enseignement "latin" du séminaire: "nous n'avons pas besoin d'autres écoles que russes dans les diocèses, car dans les églises chez nous, ce n'est pas en latin, ni dans d'autres langues étrangères que l'on lit et que l'on chante la messe, mais en russe" (Знаменский, Духовные школы, 487-488). Ce genre de critiques était tout de même rare. 